\title{
Atomic mean-square displacements and the critical-voltage effect in cubic solid solutions
}

\author{
By C. G. ShIRLey \\ Motorola Inc., Semiconductor Research and Development Laboratories, \\ 5005 East McDowell Road, Phoenix, Arizona 85008, U.S.A. \\ and R. M. Fisher \\ U.S. Steel Corporation, Research Laboratory, Monroeville, \\ Pennsylvania 15146, U.S.A.
}

[Received 19 April 1978 and accepted 9 August 1978]

\begin{abstract}
The critical-voltage phenomena observed in high-voltage electron microscope images of bend contours as well as in corresponding Kikuchi or convergent-beam diffraction patterns provide sensitive methods of determining submicroscopic alloy parameters such as Debye temperatures, short-range order, and atomic scattering factors. Only a very limited number of critical voltages can be observed in metal crystals in the voltage range usually available, 100 to $1200 \mathrm{kV}$, so that quantitative interpretation of the data must be based on a few-parameter model which incorporates all the pertinent factors. A satisfactory two-parameter model has been developed which can be used to interpret or compute the critical voltages of substitutional solid solutions as functions of composition, temperature and shortrange order. In the alloy systems $\mathrm{Fe}-\mathrm{Cr}, \mathrm{Ni}-\mathrm{Au}, \mathrm{Cu}-\mathrm{Au}$ and $\mathrm{Cu}-\mathrm{Al}$, sufficient critical voltage data are available to derive the model parameters which pertain to atomic bonding in the lattice. In addition to atomic scattering amplitudes, the critical voltage depends strongly on the atomic mean-square displacements. The static contribution to the mean-square displacements is large in alloys with large atomic-radius disparity, and is especially sensitive to short-range order in f.c.c. solid solutions. Well-defined best estimates for the model parameters are used to predict the critical voltage and its sensitivity to composition, temperature and short-range order for a large number of solid solutions. Systems for which critical-voltage studies may be of considerable interest are indicated.
\end{abstract}

\section{§ 1. INTRODUCTION}

Detailed examination of electron diffraction patterns from precisely oriented thick crystals at accelerating voltages greater than about $100 \mathrm{kV}$ has revealed that at certain critical voltages, $V_{c}$, second-order Kikuchi lines vanish and other characteristic changes occur (Nagata and Fukuhara 1967, Uyeda 1968, Watanabe, Uyeda and Kogiso 1968, Fisher, Lally, Humphreys and Metherell 1970, Thomas 1972, Bell and Thomas 1972, Steeds, Jones, Rackham and Shannon 1976). This effect has been used for the determination of atomic scattering factors and sometimes Debye temperatures in pure metals (for review see Lally, Humphreys, Metherell and Fisher 1972, Thomas, Shirley, Lally and Fisher 1974).

It has been recognized for some time (Lally et al. 1972, Shirley, Thomas, Lally and Fisher 1974, Sinclair, Goringe and Thomas 1975) that the criticalvoltage effect may find even more effective application in alloy studies. The information obtained from a critical-voltage experiment is much the same as 
can be found from an X-ray diffraction measurement of the Debye-Waller angular attenuation of Bragg reflections. However, whereas X-ray techniques average a signal from a relatively large volume of material, criticalvoltage measurements can be carried out in small volumes of crystal, $1 \mu \mathrm{m}$ or less in diameter. Moreover, one always has the image available to select the phase of interest or to measure the distance of the area under study from an interface, etc. The small sampling volume also makes specimen preparation much less difficult than for a comparable $\mathrm{X}$-ray study so that it is feasible to study composition as a variable. In spite of its potential, and the increased availability of high-voltage electron microscopes, critical-voltage measurements have not been widely used in metallurgical applications. The technique has been used for studying local composition variations in Ni-base alloys (Butler 1972, 1973), composition variation of the Debye temperature in $\mathrm{Fe}-\mathrm{Cr}$ alloys (Shirley, Lally, Thomas and Fisher 1975) and ordering in ordered $\mathrm{Cu}_{3} \mathrm{Au}$ and $\mathrm{Ni}_{4} \mathrm{Mo}$ (Sinclair et al. 1975), but there is little else for alloys apart from some scattered and uninterpreted critical voltages.

A possible reason for this situation is that there is no simple, universal few-parameter model to interpret critical voltage data for alloys or to indicate the feasibility of a particular critical voltage study. In this paper an analysis is presented which can be used to predict or interpret critical voltages in b.c.c. and f.c.c. substitutional solid solutions. Similar principles can be used for alloys exhibiting long-range order, but specific models must be written down for each ordered structure and consequently they have narrower applicability. The model derived in the present paper takes into account the static as well as the thermal (vibrational) mean-square displacements of the atoms. The central importance of the static displacements in both ordered and disordered alloys in analysis of alloy critical-voltage data is not widely appreciated. We shall see that the static mean-square displacements are very sensitive to shortrange order, especially in f.c.c. alloys, and are large if the elements have appreciable atomic-radius disparity. The model derived in the following section sacrifices some of the precision of a rigorous calculation based on the particular interatomic potentials (see, for example, Shirley 1974) to achieve a few-parameter model with broad applicability. This is necessary because of the limited number of critical voltages and experimental variables (temperature, composition) one has available to determine model parameters. Preliminary reports of the results presented here have been given by Shirley et al. (1974), Shirley (1975), Thomas et al. (1974) and Shirley and Fisher (1977).

In $\S 2$ we derive the model and describe the key parameters. The model is used in $\S 3$ to analyse critical-voltage data for $\mathrm{Fe}-\mathrm{Cr}, \mathrm{Ni}-\mathrm{Au}, \mathrm{Cu}-\mathrm{Au}$ and $\mathrm{Cu}-\mathrm{Al}$ solid solutions. The discussion illustrates the relative importance of the various alloy parameters. In $\S 4$ the theory is used to estimate the composition and short-range-order sensitivities of a large number of alloys. It is hoped that this will serve as a guide to future critical-voltage work on solid solutions.

\section{§ 2. THEORY}

Several different diffraction conditions can result in minimum intensity in high-order reflections at a critical acceleration voltage. One of the more easily observed and most thoroughly studied of these critical-voltage effects is 
the extinction at $V_{\mathrm{c}}$ of the second-order reflection in a row of reflections from a particular set of crystal planes when the Bragg condition for the second-order reflection is satisfied. The crystal should be oriented so no other planes are diffracting. The effect was first reported by Nagata and Fukuhara (1967) and Uyeda (1968). This critical voltage occurs when branches 2 and 3 (in the notation of Humphreys and Fisher 1971) come into contact at a Brillouin zone boundary (Metherell and Fisher 1969). The contact of the dispersion surface branches also has consequences in the Kikuchi or convergentbeam patterns which can be used for more precise determination of the critical voltage than is possible from spot patterns or bend-contour images (Thomas 1972, Bell and Thomas 1972). For substitutional solid solutions the value of the critical voltage depends on the average atomic scattering factor evaluated at the reciprocal lattice points in the row of excited reflections. Composition, temperature, and short-range order affect the critical voltage only through the average atomic scattering factor, $f$, so attention in this section is focused on factors influencing $f$ in cubic substitutional solid solutions. Once $f$ is known, it is relatively straightforward to employ the $n$-beam matrix diagonalization method of Fisher (1968) in a computer program which locates the voltage for which dispersion surfaces 2 and 3 coincide at the Brillouin zone boundary.

The average atomic scattering factor for a cubic substitutional solid solution is :

$$
f=m_{\mathrm{A}} f_{\mathrm{A}} \exp \left(-M_{\mathrm{A}}\right)+m_{\mathrm{B}} f_{\mathrm{B}} \exp \left(-M_{\mathrm{B}}\right)
$$

where

$$
M_{\mathrm{A}}=\left(8 \pi^{2} / 3\right)\left\langle u^{2}\right\rangle_{\mathrm{A}} s^{2},
$$

and similarly for $M_{\mathrm{B}}$. In these expressions $s=(\sin \psi) / \lambda$ where $\psi$ is the Bragg angle and $\lambda$ is the electron wavelength. The mole fraction of A-atoms (or B-atoms) is $m_{\mathrm{A}}$ (or $m_{\mathrm{B}}$ ) and their mean-square displacements are $\left\langle u^{2}\right\rangle_{\mathrm{A}}$ (or $\left.\left\langle u^{2}\right\rangle_{\mathrm{B}}\right)$. The atomic scattering factors in the alloy are $f_{\mathrm{A}}$ and $f_{\mathrm{B}}$. The form of eqns. (1) and (2) assumes that the environment of each site is statistically cubic and that the mean-square displacements, both thermal and static, may be calculated from a harmonic model. Krivoglaz (1969) has discussed the complications which arise when deviations from harmonicity are considered. In order to derive a simple broadly applicable model we shall, however, ignore anharmonic effects.

In principle, the atomic scattering factors $f_{\mathrm{A}}$ and $f_{\mathrm{B}}$ are functions of composition and short-range order. In practice, however, the situation is simpler because the atomic scattering factors in the solid solution are constant and equal to the free-atom scattering factors except at low scattering angles where the free-atom value is modified by the rearrangement of the outer electrons in the crystalline environment (see, for example, Lally et al. 1972). Thus only the values of $f_{\mathrm{A}}$ and $f_{\mathrm{B}}$ at the first-order reflection are significantly different from the free-atom values and it is these deviations which may depend on composition and short-range order. There is no theory which gives these deviations in terms of composition, short-range order and, say, electronegativity difference for a wide range of solid solutions. We shall see 
that measurements of these electron transfer effects may be possible in certain favourable cases, but for the most part the mean-square displacements are the dominant factor influencing the critical voltage.

The theory for evaluating $\left\langle u^{2}\right\rangle_{\mathrm{A}}$ and $\left\langle u^{2}\right\rangle_{\mathrm{B}}$ and similar correlations has been the subject of a good deal of research (see, for example, Krivoglaz 1960, 1969, Shirley 1974). Here we derive a heuristic, broadly applicable version of this theory which gives a better physical insight than the formal treatment of Shirley (1974) and which takes advantage of computer calculations of distortion fields around defects (Flinn and Maradudin 1962, Flocken and Hardy 1969). Krivoglaz (1960) had to rely on approximate manual integrations over the Brillouin zone. We also wish to tailor the theory to the criticalvoltage application by our choice of unknown parameters. It is useful to express $\left\langle u^{2}\right\rangle_{\mathrm{A}}$ and $\left\langle u^{2}\right\rangle_{\mathrm{B}}$ in terms of the correlations studied by Shirley (1974). Let $\sigma_{i}{ }^{\mathrm{A}}=(1,0)$ if there is an $(\mathrm{A}, \mathrm{B})$ atom at site $i$, and similarly for $\sigma_{i}{ }^{\mathrm{B}}$. Then

$$
\left\langle u^{2}\right\rangle_{\mathrm{A}}=\sum_{i} \sigma_{i}{ }^{\mathrm{A}} u_{i}{ }^{2} / \sum_{i} \sigma_{i}{ }^{\mathrm{A}}=\left\langle\sigma^{\mathrm{A}} u^{2}\right\rangle / m_{\mathrm{A}},
$$

where $u_{i}$ is the atomic displacement from site $i$, and where the sum is over all lattice sites. The ensemble average in the second equality is the value of the enclosed variables averaged over all sites in the crystal. Because of the relation $\sigma_{i}{ }^{\mathrm{A}}+\sigma_{i}{ }^{\mathrm{B}}=1$ it is possible to express $\sigma_{i}{ }^{\mathrm{A}}$ (and $\sigma_{i}{ }^{\mathrm{B}}$ ) in terms of $\sigma_{i}$ which has the value $\left(2 m_{\mathrm{B}},-2 m_{\mathrm{A}}\right)$ for an $(\mathrm{A}, \mathrm{B})$ atom at site $i$. This variable has the following properties which will be used later :

(i) $\left\langle\sigma_{i}\right\rangle=0$,

(ii) $\sigma_{i}^{2}=4 m_{\mathrm{A}} m_{\mathrm{B}}+2\left(m_{\mathrm{B}}-m_{\mathrm{A}}\right) \sigma_{i}$,

(iii) $\left\langle\sigma_{0} \sigma_{i}\right\rangle=4 m_{\mathrm{A}} m_{\mathrm{B}} \alpha_{0 i}$.

The final property is the relation between the pair correlation and the CowleyWarren short-range order parameter, $\alpha$ (Warren 1969). It is easily verified that $\sigma_{i}{ }^{\mathrm{A}}=m_{\mathrm{A}}+\frac{1}{2} \sigma_{i}$ which with (3) gives

and similarly

$$
\left\langle u^{2}\right\rangle_{\mathrm{A}}=\left\langle u^{2}\right\rangle+\left(2 m_{\mathrm{A}}\right)^{-1}\left\langle\sigma u^{2}\right\rangle
$$

$$
\left\langle u^{2}\right\rangle_{\mathrm{B}}=\left\langle u^{2}\right\rangle-\left(2 m_{\mathrm{B}}\right)^{-1}\left\langle\sigma u^{2}\right\rangle .
$$

Thus the problem of studying $\left\langle u^{2}\right\rangle_{\mathrm{A}}$ and $\left\langle u^{2}\right\rangle_{\mathrm{B}}$ is now reduced to the study of the correlations $\left\langle u^{2}\right\rangle$ and $\left\langle\sigma u^{2}\right\rangle$ as functions of temperature, composition and short-range order. It is possible to use the analytical theory (Shirley 1974) to derive expressions for the correlations of interest in terms of interatomic potentials, but it will be adequate for the present to take a heuristic approach with emphasis on physical interpretation. The approach will appeal to other work at various points in the development. The analytical theory shows that $\left\langle u^{2}\right\rangle$ and $\left\langle\sigma u^{2}\right\rangle$ may be regarded as having two separate components :

$$
\begin{gathered}
\left\langle u^{2}\right\rangle=\left\langle u^{2}\right\rangle_{\mathrm{t}}+\left\langle u^{2}\right\rangle_{\mathrm{s}}, \\
\left\langle\sigma u^{2}\right\rangle=\left\langle\sigma u^{2}\right\rangle_{\mathrm{t}}+\left\langle\sigma u^{2}\right\rangle_{\mathrm{s}} .
\end{gathered}
$$

The first components are explicitly temperature dependent and may be interpreted as arising from the vibrational motion, including zero-point 
motion. They are called the thermal components. On the other hand, the second components may be thought of as coming from the static distortions due to the atomic radius mismatch. These components are called static components. The problem is now reduced to a study of the four correlations on the right-hand side of eqns. (6). Note that for a pure metal, $\left\langle u^{2}\right\rangle_{\mathrm{t}}$ is the only correlation. We shall examine the thermal and static components separately.

To deal with the thermal correlations $\left\langle u^{2}\right\rangle_{\mathrm{t}}$ and $\left\langle\sigma u^{2}\right\rangle_{\mathrm{t}}$, we first note that the formal theory (Shirley 1974) shows that the latter is an order in atomicradius-mismatch parameter smaller than the former. Since the two thermal correlations are not experimentally separable, we can ignore $\left\langle\sigma u^{2}\right\rangle_{\mathrm{t}}$. To derive an expression for $\left\langle u^{2}\right\rangle_{t}$, imagine an alloy in which every site is equivalent. Take $V_{\mathrm{AA}}$ as the nearest-neighbour potential between a pair of A atoms with similar definitions for $V_{\mathrm{BB}}$ and $V_{\mathrm{AB}}$. The average interatomic potential is therefore

$$
V=P_{\mathrm{AA}} V_{\mathrm{AA}}+P_{\mathrm{BB}} V_{\mathrm{BB}}+2 P_{\mathrm{AB}} V_{\mathrm{AB}},
$$

where $P_{\mathrm{AA}}$ is the probability that a given pair of nearest-neighbour sites is occupied by A atoms. The mean atomic force constants are therefore

$$
g=P_{\mathrm{AA}} g_{\mathrm{AA}}+P_{\mathrm{BB}} g_{\mathrm{BB}}+2 P_{\mathrm{AB}} g_{\mathrm{AB}},
$$

where $g$ is related to $V$ in the same way as $g_{\mathrm{AA}}$ is related to $V_{\mathrm{AA}}$, etc. The relationship depends on the lattice type and the nature of the force constant (e.g. nearest-neighbour central, nearest-neighbour angular, etc.). For example, if $g$ is a nearest-neighbour central force constant in the f.c.c. lattice then $g=\frac{1}{2} d^{2} V / d r^{2}$, evaluated at the nearest-neighbour separation. The probabilities in (7) may be written in terms of the nearest-neighbour Cowley-Warren short-range order parameter $\alpha_{1}$, by using the relations

$$
\begin{aligned}
& P_{\mathrm{AA}}=m_{\mathrm{A}}^{2}+m_{\mathrm{A}} m_{\mathrm{B}} \alpha_{1}, \\
& P_{\mathrm{BB}}=m_{\mathrm{B}}{ }^{2}+m_{\mathrm{A}} m_{\mathrm{B}} \alpha_{1}, \\
& P_{\mathrm{AB}}=m_{\mathrm{A}} m_{\mathrm{B}}\left(1-\alpha_{1}\right) .
\end{aligned}
$$

If we also define the following parameter :

$$
\tau=2 g_{\mathrm{AB}} /\left(g_{\mathrm{AA}}+g_{\mathrm{BB}}\right)
$$

then (7) may be written

$$
g=m_{\mathrm{A}} g_{\mathrm{AA}}+m_{\mathrm{B}} g_{\mathrm{BB}}+(\tau-1)\left(1-\alpha_{1}\right) m_{\mathrm{A}} m_{\mathrm{B}}\left(g_{\mathrm{AA}}+g_{\mathrm{BB}}\right) .
$$

The deviation of $\tau$ from unity is a measure of how different $g_{\mathrm{AB}}$ is from the arithmetic mean of $g_{\mathrm{AA}}$ and $g_{\mathrm{BB}}$. It is an elementary consequence of the equipartition theorem that in the classical regime $\left\langle u^{2}\right\rangle_{\mathrm{t}}$ is proportional to the absolute temperature and inversely proportional to the average interatomic force constant. On the other hand, the quantum expression defining the alloy Debye temperature $\Theta$ is (Warren 1969)

$$
\left\langle u^{2}\right\rangle_{\mathrm{t}}=\frac{9 \hbar^{2}}{\kappa A}\left\{\frac{T \phi(\Theta / T)}{\mu \Theta^{2}}+\frac{1}{4 \mu \Theta}\right\},
$$


where $\kappa$ is Boltzmann's constant, $\hbar$ is Planck's constant, $A$ is the atomic mass unit, $\phi$ is Debye's function and $\mu=m_{\mathrm{A}} \mu_{\mathrm{A}}+m_{\mathrm{B}} \mu_{\mathrm{B}}$, where $\mu_{\mathrm{A}}$ is the atomic weight of an A-atom. Since the classical and quantum results must agree as $T \rightarrow \infty$, we have $g=C \mu \Theta^{2}$ where $C$ is a constant which depends on crystal structure, and where we have used $\phi(0)=1$. For the pure metals we have $g_{\mathrm{AA}}=C \mu_{\mathrm{A}} \Theta_{\mathrm{A}}^{2}$ where $\Theta_{\mathrm{A}}$ is the Debye temperature of the pure A-metal. Substitution of these expressions for $g, g_{\mathrm{AA}}$ and $g_{\mathrm{BB}}$ into (9) yields

$$
\mu \Theta^{2}=m_{\mathrm{A}} \mu_{\mathrm{A}} \Theta_{\mathrm{A}}^{2}+m_{\mathrm{B}} \mu_{\mathrm{B}} \Theta_{\mathrm{B}}^{2}+(\tau-1)\left(1-\alpha_{1}\right) m_{\mathrm{A}} m_{\mathrm{B}}\left(\mu_{\mathrm{A}} \Theta_{\mathrm{A}}^{2}+\mu_{\mathrm{B}} \Theta_{\mathrm{B}}{ }^{2}\right) .
$$

Equations (10) and (11) constitute a simple model expression for $\left\langle u^{2}\right\rangle_{\mathrm{t}}$. The value of $\tau$ is expected to be a constant for a given binary system, whereas $\alpha_{1}$ depends on the thermal history of each individual alloy. Equation (11) has been derived for $n$-component alloys and tested for several transition/noble metal alloys with small atomic-radius disparity (Shirley 1975).

For alloys with appreciable atomic-radius mismatch, $\left\langle u^{2}\right\rangle_{\mathrm{s}}$ and $\left\langle\sigma u^{2}\right\rangle_{\mathrm{s}}$ are important. The first step to derive a model for these correlations is to write down an expression for the displacement of an atom from its site on the average lattice due to surrounding atoms. A physically reasonable expression for the static displacement of the atom at site $j$ is

$$
\mathbf{u}_{j}=-\sum_{k} \boldsymbol{\xi}_{j k} \sigma_{k} \text {. }
$$

This shows that each site $k$ gives the atom at $j$ a push or pull from the average lattice site according to whether there is an $\mathrm{A}$ or a $\mathrm{B}$ atom at site $k$ (and independent of the occupancy of site $j$ ). Notice that the average displacement, $\langle\mathbf{u}\rangle_{\mathrm{s}}$, vanishes because of the property $\langle\sigma\rangle=0$, as it must. Equation (12) is also the leading order of the analytical theory (Krivoglaz 1969, Shirley 1974). The analytical theory gives a prescription for evaluating $\xi_{j k}$ :

$$
\xi_{0 i}=\sum_{k} \mathscr{G}_{0 k} \mathscr{W}_{i k}
$$

where $\mathscr{G}_{0 k}$ is the Green function inverse to the force-constant matrix for interatomic potential

and

$$
V=m_{\mathrm{A}}^{2} V_{\mathrm{AA}}+m_{\mathrm{B}}^{2} V_{\mathrm{BB}}+2 m_{\mathrm{A}} m_{\mathrm{B}} V_{\mathrm{AB}}
$$

$$
\mathscr{W}_{0 k}= \begin{cases}W^{\prime} \mathbf{r}_{0 k} /\left|\mathbf{r}_{0 k}\right| & \left(\mathbf{r}_{0 k}=\text { nearest-neighbour vector }\right) \\ 0 & \text { (otherwise) }\end{cases}
$$

where $W^{\prime}=\partial W / \partial r$ at nearest-neighbour separation where

$$
W=\frac{1}{2}\left[m_{\mathrm{A}} V_{\mathrm{AA}}-m_{\mathrm{B}} V_{\mathrm{BB}}+\left(m_{\mathrm{B}}-m_{\mathrm{A}}\right) V_{\mathrm{AB}}\right] .
$$

The evaluation of (13) is essentially the same as the calculation of distortions around point defects (Flinn and Maradudin 1962, Flocken and Hardy 1969). A detailed calculation based on the formal theory would involve computations similar to these. However, for a theory which is expected to encompass a wide range of alloys, it is sufficient merely to translate the point-defect 
results into the alloy case. For the f.c.c. case one may transcribe the results of Flinn and Maradudin (1962) to give

$$
\xi_{0 i}=\sqrt{ } 2\left(W^{\prime} / V^{\prime \prime}\right) \mathbf{T}_{0 i}
$$

where $V^{\prime \prime}=\partial^{2} V / \partial r^{2}$ and where $\mathbf{T}_{0 i}$ is given in table II of Flinn and Maradudin (1962). We have extended this tabulation by using a linear combination of Kubic harmonics in the asymptotic form of the Green function which matches the asymptotic behaviour of Flinn and Maradudin's tabulated Green function. The extended tabulation of $\mathbf{T}_{0 i}$ for f.c.c. is given in table 1. For b.c.c. solid solutions it is possible to use the calculated results of Flocken and Hardy (1969) for vacancies in alkali metals to obtain an expression analogous to (16).

Table 1. Dimensionless displacement field $\mathbf{T}_{0 i}$ for face-centred-cubic lattice.

\begin{tabular}{llll}
\hline$l m n$ & $T_{x}(\operatorname{lmn})$ & $T_{y}(\operatorname{lmn})$ & $T_{z}(\operatorname{lmn})$ \\
\hline 110 & $0 \cdot 1205$ & $0 \cdot 1205$ & $0 \cdot 1205$ \\
200 & $0 \cdot 0075$ & 0 & 0 \\
211 & $0 \cdot 0373$ & $0 \cdot 0242$ & $0 \cdot 0242$ \\
220 & $0 \cdot 0411$ & $0 \cdot 0411$ & 0 \\
310 & $0 \cdot 0082$ & $0 \cdot 0064$ & 0 \\
222 & $0 \cdot 0160$ & $0 \cdot 0160$ & $0 \cdot 0160$ \\
321 & $0 \cdot 0176$ & $0 \cdot 0140$ & $0 \cdot 0072$ \\
400 & $0 \cdot 0000$ & 0 & 0 \\
330 & $0 \cdot 0184$ & $0 \cdot 0184$ & 0 \\
411 & $0 \cdot 0029$ & $0 \cdot 0025$ & $0 \cdot 0025$ \\
420 & $0 \cdot 0057$ & $0 \cdot 0059$ & 0 \\
332 & $0 \cdot 0111$ & $0 \cdot 0111$ & $0 \cdot 0036$ \\
422 & $0 \cdot 0098$ & $0 \cdot 0036$ & $0 \cdot 0036$ \\
431 & $0 \cdot 0103$ & $0 \cdot 0086$ & $0 \cdot 0020$ \\
510 & $0 \cdot 0000$ & $0 \cdot 0013$ & 0 \\
521 & $0 \cdot 0031$ & $0 \cdot 0021$ & $0 \cdot 0006$ \\
440 & $0 \cdot 0091$ & $0 \cdot 0091$ & 0 \\
433 & $0 \cdot 0095$ & $0 \cdot 0078$ & $0 \cdot 0078$ \\
530 & $0 \cdot 0050$ & $0 \cdot 0038$ & 0 \\
442 & $0 \cdot 0082$ & $0 \cdot 0082$ & $0 \cdot 0008$ \\
600 & $0 \cdot 0022$ & 0 & 0 \\
532 & $0 \cdot 0064$ & $0 \cdot 0045$ & $0 \cdot 0013$ \\
\hline
\end{tabular}

In any calculation of the displacement field around a defect the most significant parameters are the nearest-neighbour central-force constant and the nearest-neighbour force $\left(\alpha_{1}\right.$ and $F(1)$, respectively, in Flocken and Hardy 1969 . Examination of the tabulated displacements in Flocken and Hardy (1969) shows that, to $10 \%$ of the largest displacement, all displacement fields around vacancies are identical when normalized by $F(1) / \alpha_{1}$, which has the dimensions of length. To a fair approximation then, the displacement field around vacancies in alkali metals is given by

$$
\mathbf{u}_{0 i}=\frac{2 F(1)}{3 \sqrt{ } 3 \alpha_{1}} \mathbf{T}_{0 i}
$$


where $\mathbf{T}_{0 i}$ is tabulated in table 2. The numerical factors in (17) have been chosen for later convenience. Table 2 was calculated by averaging the normalized displacement fields for the alkali metals studied by Flocken and Hardy (1969). A formal comparison of the theory for displacements in alloys and the theory for displacements around point defects shows that the following replacements in (17) yield an expression for $\xi_{0 i}$ :

$$
\begin{aligned}
F(1) & \rightarrow W^{\prime} \\
\alpha_{1} & \rightarrow \frac{1}{3}\left(V^{\prime \prime}+\frac{4 V^{\prime}}{\sqrt{ } 3 a}\right),
\end{aligned}
$$

where $a$ is the lattice parameter. The second term on the right of (18b) can be shown to be at most $25 \%$ of the first term, and for the sake of a broadly applicable theory we shall ignore it. Thus an approximation broad enough to cover many b.c.c. alloys is

$$
\xi_{0 i}=\frac{2 W^{\prime}}{\sqrt{ } 3 V^{\prime \prime}} \mathbf{T}_{0 i} .
$$

It is easy to see from (14) and (15) that

$$
W=\frac{1}{4}\left(\frac{d V}{d m_{\mathrm{A}}}-V^{\prime} \frac{d r_{0}}{d m_{\mathrm{A}}}\right),
$$

Table 2. Dimensionless displacement field $\mathbf{T}_{\mathbf{0} i}$ for body-centred-cubic lattice.

\begin{tabular}{lrrl}
\hline$l m n$ & $T_{x}(\operatorname{lmn})$ & $T_{y}(\operatorname{lmn})$ & $T_{z}(\operatorname{lmn})$ \\
\hline 111 & $0 \cdot 2470$ & $0 \cdot 2470$ & $0 \cdot 2470$ \\
200 & $-0 \cdot 2597$ & 0 & 0 \\
220 & $0 \cdot 0717$ & $0 \cdot 0717$ & 0 \\
222 & $0 \cdot 1341$ & $0 \cdot 1341$ & $0 \cdot 1341$ \\
311 & $-0 \cdot 0326$ & $-0 \cdot 0147$ & $-0 \cdot 0147$ \\
331 & $0 \cdot 0403$ & $0 \cdot 0403$ & $0 \cdot 0022$ \\
333 & $0 \cdot 0775$ & $0 \cdot 0775$ & $0 \cdot 0775$ \\
400 & $-0 \cdot 0341$ & 0 & 0 \\
420 & $-0 \cdot 0027$ & $-0 \cdot 0010$ & 0 \\
422 & $-0 \cdot 0089$ & $0 \cdot 0034$ & $0 \cdot 0.034$ \\
440 & $0 \cdot 0276$ & $0 \cdot 0276$ & 0 \\
442 & $0 \cdot 0257$ & $0 \cdot 0257$ & $0 \cdot 0032$ \\
444 & $0 \cdot 0460$ & $0 \cdot 0460$ & $0 \cdot 0460$ \\
511 & $-0 \cdot 0125$ & $-0 \cdot 0015$ & $-0 \cdot 0015$ \\
531 & $0 \cdot 0010$ & $0 \cdot 0016$ & $0 \cdot 0013$ \\
533 & $0 \cdot 0017$ & $0 \cdot 0085$ & $0 \cdot 0085$ \\
551 & $0 \cdot 0188$ & $0 \cdot 0188$ & $0 \cdot 0014$ \\
555 & $0 \cdot 0284$ & $0 \cdot 0284$ & $0 \cdot 0284$ \\
600 & $-0 \cdot 0105$ & 0 & 0 \\
620 & $-0 \cdot 0052$ & $-0 \cdot 0018$ & 0 \\
622 & $-0 \cdot 0063$ & $0 \cdot 0008$ & $0 \cdot 0008$ \\
640 & $0 \cdot 0025$ & $0 \cdot 0026$ & 0 \\
\hline
\end{tabular}


where $r_{0}$ is the nearest-neighbour separation. So, taking the derivative

$$
\begin{aligned}
W^{\prime} & \simeq-\frac{1}{4 \sqrt{ } 2} V^{\prime \prime} \frac{d a}{d m_{\mathrm{A}}} \quad \text { (f.c.c.) } \\
& \simeq-\frac{\sqrt{ } 3}{8} V^{\prime \prime} \frac{d a}{d m_{\mathrm{A}}} \quad \text { (b.c.c.) }
\end{aligned}
$$

where we have dropped $d V^{\prime} / d m_{\mathrm{A}}$ because angular forces are usually small. Substituting (20) into (16) and (19) we find

$$
\boldsymbol{\xi}_{0 i}=-\frac{1}{4} \frac{d a}{d m_{\mathrm{A}}} \mathbf{T}_{0 i}=-\frac{1}{4} \gamma a \eta \mathbf{T}_{0 i},
$$

for f.c.c. or b.c.c. depending on whether table 1 or 2 is used. Note that $\mathbf{T}_{\mathbf{0 0}}=0$. We have defined $\eta$ as

$$
\eta=\frac{d(\ln a)}{d m_{\mathrm{A}}}
$$

and we have introduced the parameter $\gamma$. In the derivation leading to (21) $\gamma$ has the value unity, but for fitting data to the model it is desirable to have a distortion field with an adjustable amplitude. Deviations from $\gamma=1$ might indicate the influence of the second term in $(18 b)$ or the other approximations made to obtain a broadly applicable model. In any case, $\gamma$ should be near unity and in situations where no data is available $\gamma=1$ is a good estimate.

Expressions for the static correlations $\left\langle u^{2}\right\rangle_{\mathrm{s}}$ and $\left\langle\sigma u^{2}\right\rangle_{\mathrm{s}}$ may be derived by using eqns. (12) and (21) in conjunction with table 1 or 2 . From eqn. (12)

$$
\begin{aligned}
\left\langle u^{2}\right\rangle_{\mathrm{s}} & =\sum_{k l} \xi_{0 k} \cdot \xi_{0 l}\left\langle\sigma_{k} \sigma_{l}\right\rangle \\
& =4 m_{\mathrm{A}} m_{\mathrm{B}} \sum_{k l} \xi\left(\mathbf{r}_{0 k}\right) \cdot \boldsymbol{\xi}\left(\mathbf{r}_{0 l}\right) \alpha\left(\mathbf{r}_{0 k}-\mathbf{r}_{0 l}\right)
\end{aligned}
$$

where we have made the functional dependence on lattice sites more explicit and where we have used $(4 c)$. A change in summation variable and substitution of (21) leads to

$$
\left\langle u^{2}\right\rangle_{\mathrm{s}}=\frac{1}{4} m_{\mathrm{A}} m_{\mathrm{B}} \gamma^{2} a^{2} \eta^{2}\left(C_{0}+\sum_{n=1}^{\infty} C_{n} \alpha_{n}\right)
$$

where

$$
\begin{aligned}
& C_{0}=\sum_{k} \mathbf{T}\left(\mathbf{r}_{0 k}\right) \cdot \mathbf{T}\left(\mathbf{r}_{0 k}\right), \\
& C_{n}=\sum_{k n} \mathbf{T}\left(\mathbf{r}_{0 k}\right) \cdot \mathbf{T}\left(\mathbf{r}_{0 k}+\boldsymbol{\delta}_{n}\right) .
\end{aligned}
$$

In (22) $\alpha_{n}$ is the $n$ th-neighbour Cowley-Warren short-range order parameter and in $(23 b)$ the sum over $n$ is over the set of $n$ th-neighbour vectors $\left\{\boldsymbol{\delta}_{n}\right\}$. The sums in (23) were performed over successively larger volumes and convergence to within $4 \%$ was obtained at the largest volume. The largest volume had radius equal to the largest interatomic vector shown in table 1 
Table 3. Values of the lattice sum $C_{n}$ in eqn. (22).

\begin{tabular}{ccc}
\hline$n$ & F.c.c. & B.c.c. \\
\hline 0 & $0 \cdot 533$ & $2 \cdot 837$ \\
1 & $3 \cdot 163$ & $2 \cdot 123$ \\
2 & $0 \cdot 926$ & $1 \cdot 422$ \\
3 & $2 \cdot 413$ & $-2 \cdot 431$ \\
\hline
\end{tabular}

or 2. The values for $C_{n}$ are given in table 3 for f.c.c. and b.c.c. In similar fashion we write

$$
\left\langle\sigma u^{2}\right\rangle_{\mathrm{s}}=\sum_{k l} \xi\left(\mathbf{r}_{0 k}\right) \cdot \xi\left(\mathbf{r}_{0 l}\right)\left\langle\sigma_{0} \sigma_{k} \sigma_{l}\right\rangle
$$

Special cases in the sum must be considered separately. In (24) the cases $k=0, l=0$ and $k=l=0$ in the sum give no contribution since $\xi(0)=0$. However, $k=l \neq 0$ does give a contribution so (24) becomes

$$
\begin{aligned}
\left\langle\sigma u^{2}\right\rangle_{\mathrm{s}}=\sum_{k \neq l \neq 0} \xi\left(\mathbf{r}_{0 k}\right) \cdot \xi\left(\mathbf{r}_{0 l}\right) & \left\langle\sigma_{0} \sigma_{k} \sigma_{l}\right\rangle \\
& +2\left(m_{\mathrm{B}}-m_{\mathrm{A}}\right) \sum_{l \neq 0} \xi\left(\mathbf{r}_{0 l}\right) \cdot \xi\left(\mathbf{r}_{0 l}\right)\left\langle\sigma_{0} \sigma_{l}\right\rangle,
\end{aligned}
$$

where we have used $\left\langle\sigma_{0} \sigma_{l}^{2}\right\rangle=2\left(m_{\mathrm{B}}-m_{\mathrm{A}}\right)\left\langle\sigma_{0} \sigma_{l}\right\rangle$, which is a special case of $(4 b)$. Triplet correlations are usually assumed to be negligible so the first term will be dropped. We note in passing that there may be favourable circumstances for the detection of the effect of triplet correlations through the first term of (25) in equiatomic alloys $\left(m_{\mathrm{A}}=m_{\mathrm{B}}\right)$. Non-zero triplet correlations in equiatomic alloys indicate non-zero multisite $(>2)$ interaction potentials (Clapp 1968). With triplets dropped (25) becomes

$$
\left\langle\sigma u^{2}\right\rangle_{\mathrm{s}}=\frac{1}{2} m_{\mathrm{A}} m_{\mathrm{B}}\left(m_{\mathrm{A}}-m_{\mathrm{B}}\right) \gamma^{2} a^{2} \eta^{2} \sum_{n=1}^{\infty} D_{n} \alpha_{n},
$$

where

$$
D_{n}=Z_{n} T^{2}\left(\delta_{n}\right)
$$

in which $Z_{n}$ is the $n$th shell coordination number. Values for $D_{n}$ for f.c.c. and b.c.c. are given in table 4. Equations (22) and (26) in conjunction with tables 3 and 4 are the complete model expressions for the static correlations. Krivoglaz (1960) has derived an expression similar to (22) for the case of the f.c.c. lattice, and his conclusions about the sensitivity of $\left\langle u^{2}\right\rangle_{\mathrm{s}}$ to short-range

Table 4. Values of the coefficients $D_{n}$ in eqn. (26).

\begin{tabular}{lll}
\hline$n$ & F.c.c. & B.c.c. \\
\hline 1 & $0 \cdot 3485$ & $1 \cdot 464$ \\
2 & $0 \cdot 0003$ & $0 \cdot 4015$ \\
3 & $0 \cdot 0614$ & $0 \cdot 1234$ \\
\hline
\end{tabular}


order in f.c.c. correspond with ours. He did not derive $\left\langle\sigma u^{2}\right\rangle_{\mathrm{s}}$ or study the b.c.c. case and he had to rely on a Houston's formula integration over the Brillouin zone, rather than a direct lattice summation. Detailed examination of the derivation of (22) and (26) reveals that the short-range order parameters appearing in (22) reflect correlations in site occupancy among neighbours of an average site, whereas the short-range order parameters in (26) refer to correlations between an average site and its neighbours. This is consistent with the observation that $\left\langle\sigma u^{2}\right\rangle$ is the correlation which distinguishes between mean-square displacements of the different atoms (see eqns. (5)). For vanishing short-range order, or for the equiatomic composition (except for triplet correlations), $\left\langle u^{2}\right\rangle_{\mathrm{A}}$ and $\left\langle u^{2}\right\rangle_{\mathrm{B}}$ are identical. Note in passing that any correlation function involving static displacements (e.g. $\left\langle\sigma_{i} \sigma_{j} u_{k} u_{l}\right\rangle_{\mathrm{s}}$, etc.) may be evaluated in terms of purely compositional correlations (e.g. $\left\langle\sigma_{i} \sigma_{j} \sigma_{k} \sigma_{i}\right\rangle$, etc.) via eqns. (12) and (21) and tables 1 and 2 . More general correlations such as these arise in, for example, the theory of diffuse scattering from alloys.

Equations (1), (2), (5), (6), (10), (11), (22) and (26) constitute a complete model for the composition, temperature and short-range order dependence of the critical voltages of cubic solid solutions. The model has a number of undetermined parameters the determination of which may be regarded as the object of a critical-voltage study of an alloy. The model may also be used predictively if best estimates for these parameters are chosen. The model parameters are the following :

(i) $\tau$-defined by eqn. (8). If the alloy forms a continuous solid solution, and the Debye temperatures of the terminal elements are known, $\tau$ may be determined from a measurement of an alloy Debye temperature using eqn. (11). In principle it is desirable to use a highly disordered alloy so that $\alpha_{1} \simeq 0$, but in practice the effect of $\alpha_{1}$ is small (see below). In the absence of data, $\tau=1$, corresponding to an arithmetic mean unlike-atom force constant, is a good estimate.

(ii) $\Theta_{\mathrm{B}}$ - solute atom Debye temperature. Often, solid solubility is not complete so that the pure solute and solvent are not isostructural, for example $\mathrm{Si}$ in $\mathrm{Fe}$. In such a case both $\tau$ and $\Theta_{\mathrm{B}}$ are unknown parameters. To determine them, one can measure $\Theta$ in two solid solutions and write down two simultaneous equations derived from (11) which may be solved for $\Theta_{B}$ and $\tau$. $\Theta_{B}$ is the Debye temperature of the pure solute if it had the solvent's structure (e.g. 'b.c.c. $\mathrm{Si}$ ' in the above example). In the absence of data the actual Debye structure of the pure solute is to be used, irrespective of structure.

(iii) Low-angle $f_{\mathrm{A}}, f_{\mathrm{B}}$. Deviations from the free-atom values of the atomic scattering factors, especially at low angles, can cause significant variations in $V_{\text {c. }}$ A good way to determine the value of the atomic scattering factor at the first-order reflection for a pure metal or an alloy in which static displacements are negligible is to fit to the temperature variation of $V_{\mathrm{c}}$. For example, one would adjust the atomic scattering factor for the first-order reflection until the values of $\left\langle u^{2}\right\rangle$ deduced from the critical voltages at two temperatures give the same Debye temperature when (10) is used. This gives $\Theta$ as well as the atomic scattering factor. An interesting study which apparently has 
not been tried is to choose a system with negligible atomic radius disparity and measure the temperature dependence of $V_{\mathrm{c}}$ for several compositions, including the pure metals. Since $\left\langle u^{2}\right\rangle_{\mathrm{s}} \simeq 0$ and $\left\langle\sigma u^{2}\right\rangle \simeq 0$ for such a system, eqn. (1) reduces to

$$
f=\exp (-M) \bar{f}
$$

where $M=\left(8 \pi^{2} / 3\right)\left\langle u^{2}\right\rangle_{\mathrm{t}} s^{2}$ and $\bar{f}=m_{\mathrm{A}} f_{\mathrm{A}}+m_{\mathrm{B}} f_{\mathrm{B}}$. Here $f_{\mathrm{A}}$ and $f_{\mathrm{B}}$ are the atomic scattering factors in the alloy. On the other hand we define $f_{\mathrm{A}}{ }^{\prime}$ and $f_{\mathrm{B}}{ }^{\prime}$ as the atomic scattering factors in the respective pure metals. The experiment will yield $\bar{f}-m_{\mathrm{A}} f_{\mathrm{A}}{ }^{\prime}-m_{\mathrm{B}} f_{\mathrm{B}}{ }^{\prime}$ as a function of composition and will give an indication of charge redistribution in the alloy. For alloys with appreciable atomic-radius disparity, uncertainties in $\left\langle u^{2}\right\rangle$ and $\left\langle\sigma u^{2}\right\rangle$ make a determination of $\bar{f}$ unfeasible, and it is better to regard $f_{\mathrm{A}}$ and $f_{\mathrm{B}}$ as known and approximate them by $f_{\mathrm{A}}{ }^{\prime}$ and $f_{\mathrm{B}}{ }^{\prime}$. In the analysis in the next section we assume $f_{\mathrm{A}}=f_{\mathrm{A}}{ }^{\prime}$ and $f_{\mathrm{B}}=f_{\mathrm{B}}{ }^{\prime}$ where $f_{\mathrm{A}}{ }^{\prime}$ and $f_{\mathrm{B}}{ }^{\prime}$ are Doyle-Turner (1968) atomic scattering factors modified to fit pure-metal critical voltage data where possible (Thomas et al. 1974).

(iv) $\gamma$-static-displacement-amplitude factor. This factor is of order unity and should be relatively independent of composition. To measure this parameter it is necessary to prepare an alloy which has negligible short-range order $\left(\alpha_{1} \simeq 0\right)$. This often requires a compromise between solute dilution and quench rate. Ideally one requires a very rapidly quenched concentrated solid solution. It is worth noting that the process of ordering has a diffusion length on the order of atomic diameters which can result in very rapid diffusional relaxation of $\alpha_{1}$. Mozer, Keating and Moss (1968) give an example of the type of analysis required to choose a quench rate. To determine $\gamma$, one analyses the temperature variation of $V_{\mathrm{c}}$ on the totally disordered alloy at temperatures where the atomic configuration is 'frozen'. The cases of $\mathrm{NiAu}$ and $\mathrm{CuAu}$ described below are examples of this. In the absence of data, $\gamma=1$ is the best estimate.

(v) $\alpha_{1}, \alpha_{2}$, etc.-short-range order. These parameters depend on the detailed thermal history of the alloy. Determination of $\alpha_{1}$ is made in the same way as that for $\gamma$ except that an assumed or predetermined value of $\gamma$ is used. Perhaps $\gamma$ would be determined for a composition at which ordering can be suppressed by a fast quench. It is only practical to determine $\alpha_{1}$ with $\alpha_{2}$, etc., assumed to be zero.

The above discussion emphasizes the importance of measuring critical voltages at two temperatures at least, especially for alloys. Essentially, this enables a separation of the thermal and static components of the mean-square displacements. In the next section some of the points made in this section will be illustrated by specific examples.

\section{§3. Analysis of CRItical-voltage Data For SEveral solid solutions}

\section{1. $\mathrm{Fe}-\mathrm{Cr}$}

The static displacements in this system are negligible for all compositions because the atomic diameters of $\mathrm{Fe}$ and $\mathrm{Cr}$ differ by only $0.6 \%$. Shirley et al. (1975) carried out a critical-voltage study of $\mathrm{Fe}, \mathrm{Cr}$ and their disordered alloys. 
The pure-metal low-angle scattering factors and Debye temperatures were determined by fitting to the temperature variation of the pure-metal critical voltages (see the original work for details). With these parameters in hand $\tau$ could be determined by fitting to room-temperature critical-voltage data at one or more intermediate compositions. A value of $\tau=0.72$ gave the best fit. In fig. 1 the sensitivity of the mean-square displacements and the 220 critical voltage to $\tau$ is illustrated. Static mean-square displacements are too small to be seen in this plot. This alloy is unusual in that the strongest

Fig. 1

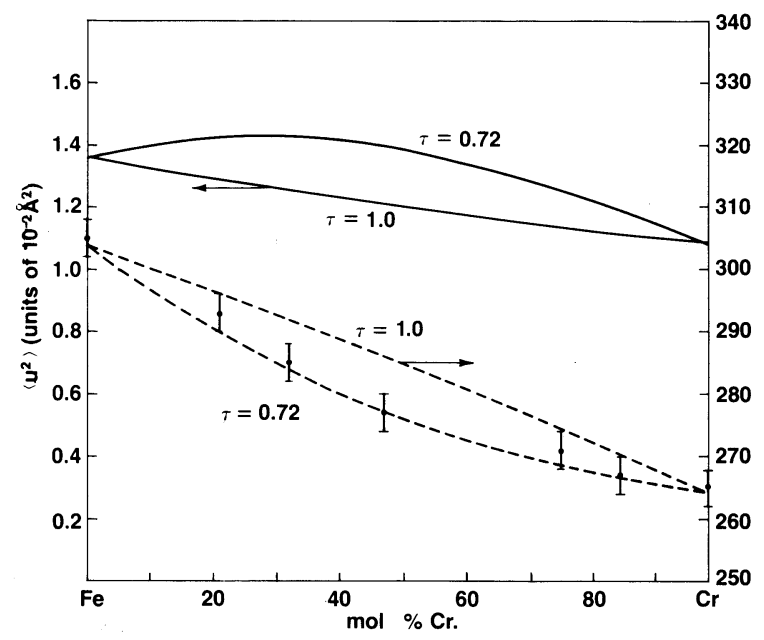

Room-temperature $(298 \mathrm{~K})$ thermal mean-square displacements (solid lines) and 220 critical voltages (dashed lines) for $\mathrm{Fe}-\mathrm{Cr}$ alloys for two values of $\tau$. Experimental values of $V_{c}$ (Shirley et al. 1975) are also shown. Static mean-square displacements are too small to plot. $\theta(\mathrm{Fe})=424 \mathrm{~K}$ and $\theta(\mathrm{Cr})=495 \mathrm{~K}$ are assumed.

effect of short-range order occurs through the thermal, not static, meansquare displacements. None the less the effect is very small. Generally the maximum change in $\alpha_{1}$ before long-range ordering sets in is given by $\Delta \alpha_{1} \simeq 0 \cdot 2$ (Moss and Clapp 1968). In equiatomic FeCr, where the effect of $\alpha_{1}$ is greatest (see eqn. (11)), this change in $\alpha_{1}$ gives a change in the room-temperature critical voltage of less than $1 \%$. It is generally true that short-range order influences the thermal mean-square displacements very little, whereas we shall see below that the influence of short-range order on the static meansquare displacements can be very significant. The $\mathrm{Fe}-\mathrm{Cr}$ system is a good candidate for a critical-voltage study of charge transfer effects.

\section{2. $N i-A u$}

In the above example one could be confident that all of the mean-square displacements were thermal in origin. However, in $\mathrm{Ni}-\mathrm{Au}$ there is a large atomic-radius disparity $(20 \%)$ which leads to an appreciable static component 
of the mean-square displacements. Measurement of the critical voltage at several temperatures makes it possible to separate the thermal and static components. Assuming no short-range order, $\left\langle\sigma u^{2}\right\rangle=0$ and $f$ has the form of (27) but with $\left\langle u^{2}\right\rangle_{\mathrm{t}}$ replaced by $\left\langle u^{2}\right\rangle=\left\langle u^{2}\right\rangle_{\mathrm{t}}+\left\langle u^{2}\right\rangle_{\mathrm{s}}$. Variation of $\left\langle u^{2}\right\rangle$ to bring the computed critical voltages into agreement with the experimental values (measured by J. S. Lally 1974, private communication) leads to the values of $\left\langle u^{2}\right\rangle$ plotted against temperature in fig. 2 for $\mathrm{Ni}(83)-\mathrm{Au}$. The atomic scattering factors and pure-metal Debye temperatures $(\Theta(\mathrm{Ni})=390 \mathrm{~K}$, $\Theta(\mathrm{Au})=185 \mathrm{~K}$ ) which fitted the pure-metal critical-voltage data (Thomas et al. 1974) were used in the analysis. Essentially, the slope of the best fit of the data in fig. 2 gives the alloy Debye temperature (and hence $\tau$ via eqn. (11)) and the intercept on the $T=0$ axis gives $\gamma$ (assuming $\alpha_{1}=0$, etc.) via (22). The best fit gives $\tau=1 \cdot 87$ and $\gamma=1 \cdot 23$.

Fig. 2

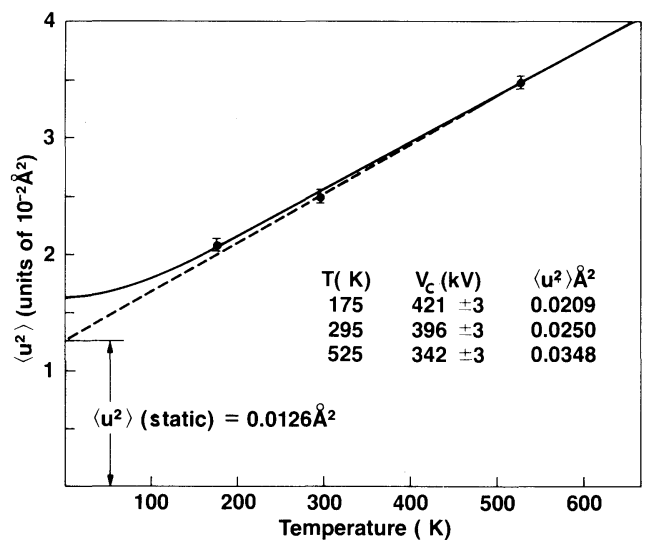

Total mean-square displacement in $\mathrm{Ni}(83)-\mathrm{Au}$ as a function of temperature as determined from the 400 critical voltage. The best theoretical fit is shown as a solid line. The classical asymptote is the broken line.

Except for the influence of short-range order, $\gamma$ and $\tau$ completely define the model. The thermal and static mean-square displacements for the experimental $\gamma$ and $\tau$ are plotted against composition at room-temperature in fig. 3 . Vanishing short-range order is assumed. The very large static component is apparent. Variation of the static and thermal mean-square displacements with $\alpha_{1}$ is given in fig. 4 for a $\mathrm{Ni}(70)-\mathrm{Au}$ alloy. The influence of short-range order on the static mean-square displacements is quite appreciable whereas the thermal component has only a weak dependence. The mean-square displacements in fig. 3 have been used to plot the zero short-range order room temperature 400 critical voltage as a function of composition in fig. 5. The data of Butler (1972) as well as the room-temperature point in fig. 2 are superimposed on the plot. Both $\mathrm{Ni}(83)-\mathrm{Au}$ samples were taken from the 
Fig. 3

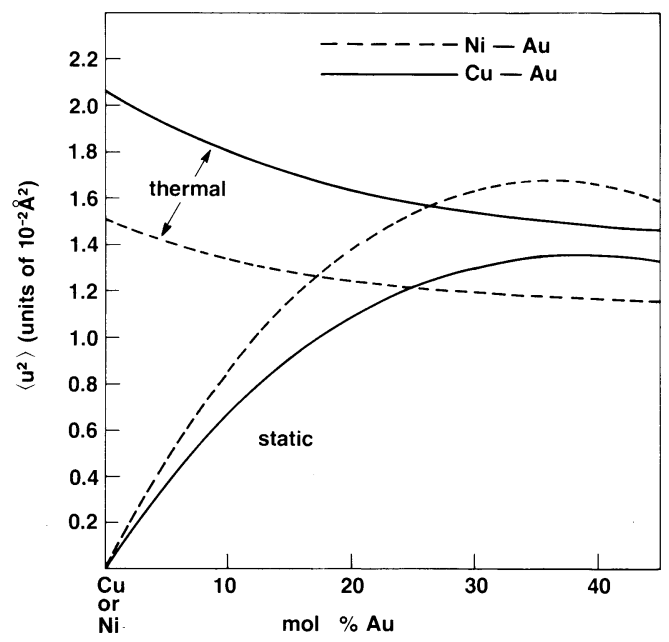

Static and room-temperature $(298 \mathrm{~K})$ thermal mean-square displacements as a function of $\mathrm{Au}$ content in $\mathrm{Ni}-\mathrm{Au}$ and $\mathrm{Cu}-\mathrm{Au}$ solid solutions. Calculated from the model assuming the best critical-voltage-determined parameters: For $\mathrm{Ni}-\mathrm{Au}, \theta(\mathrm{Ni})=390 \mathrm{~K}, \theta(\mathrm{Au})=185 \mathrm{~K}, \gamma=1 \cdot 23, \tau=1 \cdot 87$, while for $\mathrm{Cu}-\mathrm{Au}$, $\theta(\mathrm{Cu})=320 \mathrm{~K}, \theta(\mathrm{Au})=185 \mathrm{~K}, \gamma=1 \cdot 34$ and $\tau=1 \cdot 76$. Zero short-range order assumed in both cases.

same alloy. The depressed values of the critical voltage for the higher Aucontent alloys are consistent with a certain amount of clustering (atoms preferring their own kind as nearest-neighbours). These alloys are known to

Fig. 4

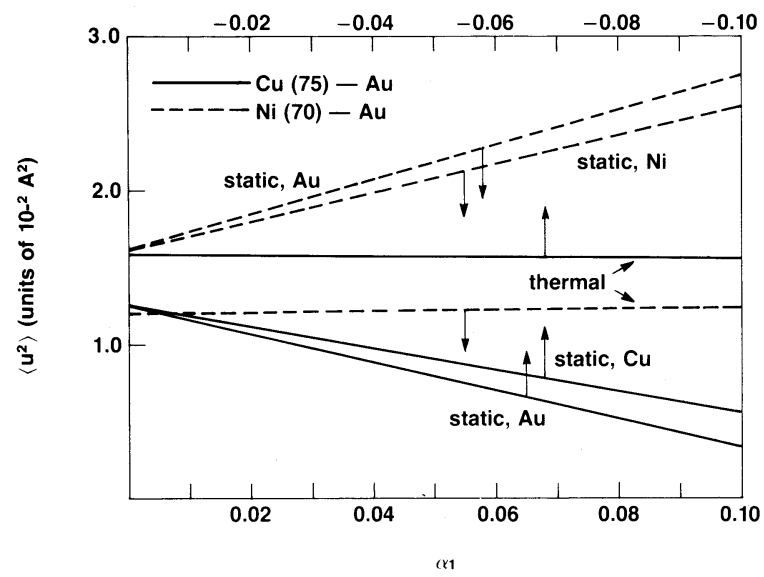

Static and room-temperature $(298 \mathrm{~K})$ thermal mean-square displacements as a function of clustering short-range order $\left(\alpha_{1}>0\right)$ in $\mathrm{Ni}(70)-\mathrm{Au}$ and ordering short-range order $\left(\alpha_{1}<0\right)$ in $\mathrm{Cu}(75)-\mathrm{Au}$. The parameters of fig. 3 are assumed. 
Fig. 5

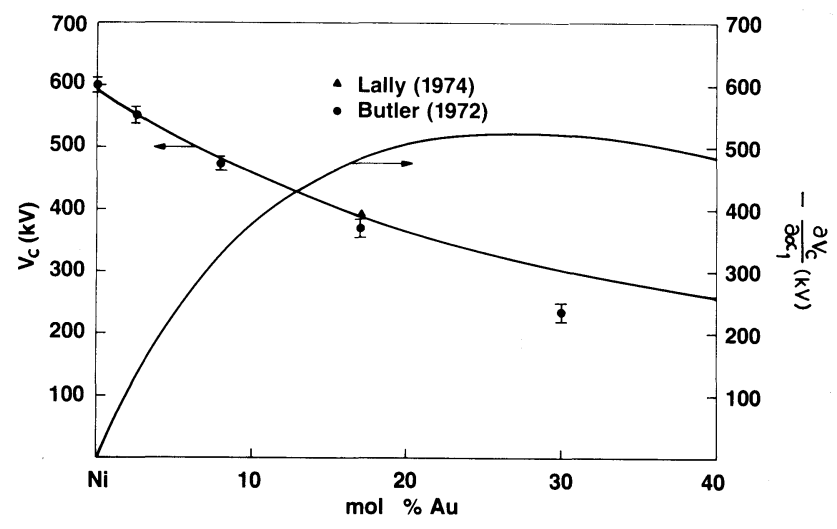

Variation of room-temperature 400 critical voltage and short-range order senstivity in $\mathrm{Ni}-\mathrm{Au}$ with composition assuming mean-square displacements of fig. 3 . Data points of Butler (1972) and Lally (1974) are shown.

have a tendency to cluster (Moss and Averbach 1967). The parameter $\partial V_{\mathrm{c}} / \partial \alpha_{1}$ is a measure of the sensitivity of the critical voltage to changes in $\alpha_{1}$ and it is also plotted in fig. 5. A depression in the critical voltage becomes more likely as one approaches the spinodal and short-range order becomes increasingly difficult to quench out. The data in fig. 5 bear this out. For the $30 \% \mathrm{Au}$ alloy the critical-voltage depression is $\Delta V_{\mathrm{c}}=-69 \pm 17 \mathrm{kV}$, while $\partial V_{\mathrm{c}} / \partial \alpha_{1}=$ $-520 \mathrm{kV}$ so $\alpha_{1}=0 \cdot 13 \pm 0.03$. A similar calculation for Butler's $17 \% \mathrm{Au}$ alloy gives $\alpha_{1}=0 \cdot 04 \pm 0 \cdot 03$.

\section{3. $C u-A u$}

This alloy also has a large atomic radius mismatch between constituent atoms (about $15 \%$ ) but in contrast to $\mathrm{Ni}-\mathrm{Au}$, atoms tend to order, rather than to cluster. There is a relatively large amount of critical-voltage data

Table 5. Critical voltages and total mean-square displacements in Cu-base solid solutions $\left(V_{c}\right.$ in units of $\mathrm{kV},\left\langle u^{2}\right\rangle$ in units of $\left.10^{-2} \AA^{2}\right)$.

\begin{tabular}{|c|c|c|c|c|c|}
\hline \multirow{2}{*}{$\begin{array}{l}\text { Mol. \% } \\
\text { solute }\end{array}$} & \multicolumn{2}{|c|}{$400 \mathrm{~V}_{\text {c }}$} & \multicolumn{2}{|c|}{$222 V_{\mathrm{c}}$} & \multirow{2}{*}{ Reference } \\
\hline & $130 \mathrm{~K}$ & $298 \mathrm{~K}$ & $130 \mathrm{~K}$ & $298 \mathrm{~K}$ & \\
\hline $5 \mathrm{Au}$ & $\begin{array}{c}592 \pm 5 \\
1 \cdot 51 \pm 0 \cdot 06\end{array}$ & $\begin{array}{c}532 \pm 5 \\
2 \cdot 32 \pm 0 \cdot 07\end{array}$ & $\begin{array}{c}317 \pm 10 \\
1 \cdot 36 \pm 0 \cdot 19\end{array}$ & $\begin{array}{c}273 \pm 10 \\
2 \cdot 28 \pm 0 \cdot 23\end{array}$ & $\begin{array}{l}\text { Kuroda et al. } \\
\quad(1977)\end{array}$ \\
\hline $15 \mathrm{Au}$ & $\begin{array}{c}490 \pm 10 \\
1 \cdot 74 \pm 0 \cdot 14\end{array}$ & $\begin{array}{c}433 \pm 10 \\
2 \cdot 62 \pm 0 \cdot 18\end{array}$ & & $\begin{array}{c}<258 \\
>1 \cdot 32\end{array}$ & $\begin{array}{l}\text { Kuroda et al. } \\
(1977)\end{array}$ \\
\hline $25 \cdot 1 \mathrm{Au}$ & & $\begin{array}{c}360 \pm 10 \\
2 \cdot 75 \pm 0 \cdot 18\end{array}$ & & & $\begin{array}{l}\text { Sinclair et al. } \\
(1975)\end{array}$ \\
\hline $24 \cdot 4 \mathrm{Au}$ & & $\begin{array}{c}381 \pm 3 \\
2 \cdot 47 \pm 0 \cdot 05\end{array}$ & & $\begin{array}{c}166 \pm 2 \\
2 \cdot 41 \pm 0 \cdot 05\end{array}$ & $\begin{array}{l}\text { Thomas et al. } \\
\text { (1974) }\end{array}$ \\
\hline $15 \mathrm{Al}$ & $\begin{array}{c}733 \pm 5 \\
1 \cdot 21 \pm 0 \cdot 05\end{array}$ & $\begin{array}{c}641 \pm 10 \\
2 \cdot 32 \pm 0 \cdot 13\end{array}$ & $\begin{array}{c}394 \pm 5 \\
1 \cdot 19 \pm 0 \cdot 09\end{array}$ & $\begin{array}{c}332 \pm 10 \\
2 \cdot 41 \pm 0 \cdot 22\end{array}$ & $\begin{array}{l}\text { Kuroda et al. } \\
\quad(1977)\end{array}$ \\
\hline
\end{tabular}


for the disordered solid solutions (Kuroda, Tomokiyo and Eguchi 1977, Sinclair et al. 1975, Thomas et al. 1974) and this is summarized in table 5. The corresponding total mean-square displacements calculated by using critical-voltage corrected pure metal atomic scattering factors are also tabulated. An interesting discrepancy occurs in the 400 critical voltage data for two different $25 \%$ $\mathrm{Au}$ alloys.

Fig. 6

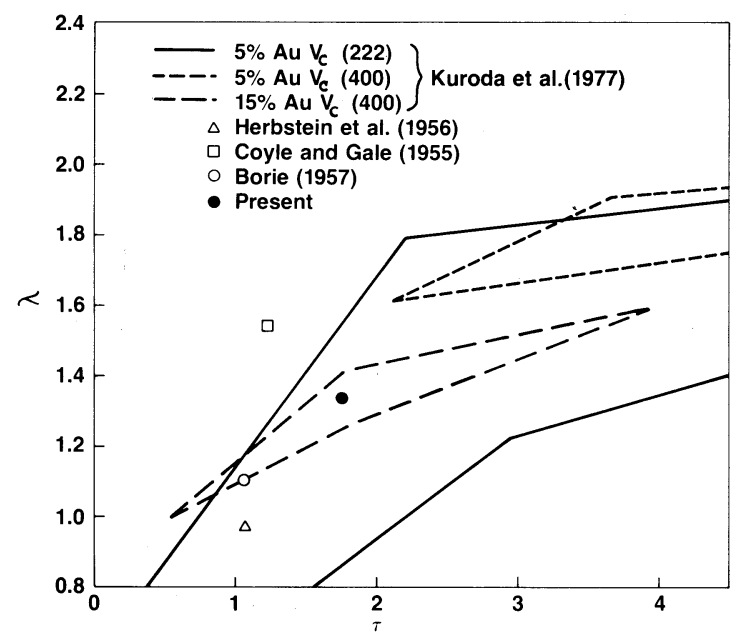

Bounds on possible values of $\gamma$ and $\tau$ for $\mathrm{Cu}-\mathrm{Au}$ deduced from data of Kuroda et al. (1977). Also shown are the values deduced from these data (see text), $\gamma=1 \cdot 34$ and $\tau=1 \cdot 76$, and values deduced from results of early X-ray studies.

The mean-square displacement data in table 5 may be analysed to give $\gamma$ and $\tau$ by finding the best fit for the model expression for $\left\langle u^{2}\right\rangle$ versus temperature. For each pair of temperatures there is a range of $\gamma$ and $\tau$ corresponding to the various ways in which the theoretical curve may be put through the $\left\langle u^{2}\right\rangle$ data and yet remain within error limits. These ranges may be represented as areas in the $\gamma-\tau$ plane shown in fig. 6 for the data of Kuroda et al. (1977). These areas assume $\Theta(\mathrm{Cu})=320 \mathrm{~K}$ and $\Theta(\mathrm{Au})=185 \mathrm{~K}$. It is interesting to compare the results of $\mathrm{X}$-ray studies of $\mathrm{Cu}-\mathrm{Au}$ alloys with the critical-voltage results. For a $25 \%$ Au alloy, Borie (1957) found $\left\langle u^{2}\right\rangle_{\mathrm{t}}=1.98 \times 10^{-2} \AA^{2}$ and $\left\langle u^{2}\right\rangle_{\mathrm{s}}=0.84 \times 10^{-2} \AA^{2}$ while Herbstein, Borie and Averbach (1956) found $\left\langle u^{2}\right\rangle_{\mathrm{t}}=1.98 \times 10^{-2} \AA^{2}$ and $\left\langle u^{2}\right\rangle_{\mathrm{s}}=0.66 \times 10^{-2} \AA^{2}$. For a $15 \%$ Au alloy Coyle and Gale (1955) found $\left\langle u^{2}\right\rangle_{\mathrm{t}}=1.93 \times 10^{-2} \AA^{2}$ and $\left\langle u^{2}\right\rangle_{\mathrm{s}}=1.22 \times 10^{-2} \AA^{2}$. It is difficult to estimate the errors in these values. The values of $\gamma$ and $\tau$ calculated from these values are plotted in fig. 6 .

Ideally, the accepted values of $\gamma$ and $\tau$ lie in the centre of the common region of overlap of the $\gamma-\tau$ areas for each temperature pair. Unfortunately, the areas in fig. 6 have no common overlap region. The temperature dependence of the critical voltage of the $5 \%$ Au alloy studied by Kuroda et al. (1977) leads to a Debye temperature $\Theta=345 \mathrm{~K}$. In view of the pure-Cu Debye 
Fig. 7

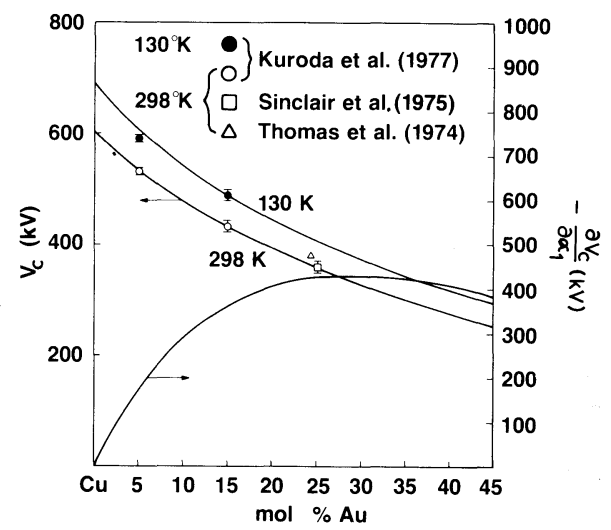

Variation of 400 critical voltage and short-range order sensitivity function in $\mathrm{Cu}-\mathrm{Au}$ with composition for two temperatures. Parameters of fig. 3 are assumed. Data from several sources is superimposed.

temperature $(320 \mathrm{~K}$ ) and the likelihood that $\mathrm{Au}$ will lower $\Theta$ (for $\mathrm{Au}, \Theta=$ $185 \mathrm{~K}$ ) it would seem that the error bars on the $5 \%$ Au 400 critical voltage should be expanded. Accordingly, our estimate of $\gamma$ and $\tau$ is made without reference to this temperature pair. As shown in fig. 6 we choose $\gamma=1 \cdot 34$ and $\tau=1 \cdot 76$. The room-temperature thermal and static mean-square displacements corresponding to this choice are shown as a function of composition in fig. 3. The large static component is apparent. These values of $\gamma$ and $\tau$ were used to compute the 400 and 222 critical voltages as a function of composition for 130 and $298 \mathrm{~K}$ assuming no short-range order. These results are shown in figs. 7 and 8 along with data from table 5 . The model fits all the data except the $130 \mathrm{~K}, 5 \% \mathrm{Au} 400$ critical voltage as explained above, and the

Fig. 8

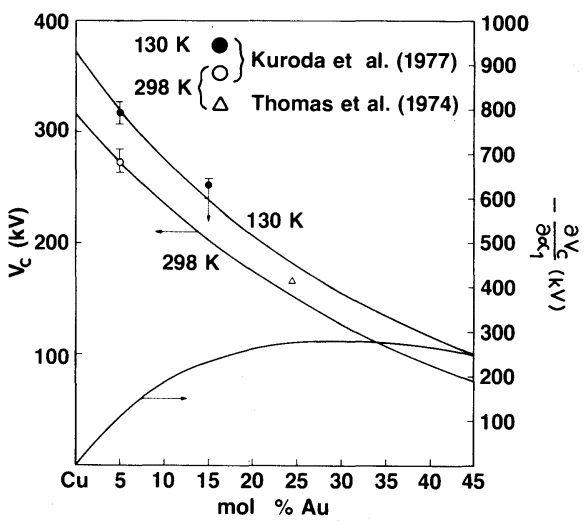

As for fig. 7 except 222 critical voltage of $\mathrm{Cu}-\mathrm{Au}$ is plotted. 
$25 \%$ Au data of Thomas et al. (1974). The critical-voltage sensitivity function $-\partial V_{\mathrm{c}} / \partial \alpha_{1}$ has also been plotted in figs. 7 and 8 and it is clear that the deviation of the triangular data points from the theoretical curves can be explained by a degree of short-range order. From fig. 7, we have $\Delta V_{\mathrm{c}}(400)=$ $19 \pm 3 \mathrm{kV}$ and $\partial V_{\mathrm{c}} / \partial \alpha_{1}=-423 \mathrm{kV}$, so $\alpha_{1}=-0.045 \pm 0.007$. On the other hand, fig. 8 gives $\Delta V_{\mathrm{c}}(222)=14 \pm 2 \mathrm{kV}$ and $\partial V_{\mathrm{c}} / \partial \alpha_{1}=-273 \mathrm{kV}$, so $\alpha_{1}=$ $-0.051 \pm 0.007$. We assume that $\alpha_{2}, \alpha_{3}$, etc., all vanish. The consistency of these values of $\alpha_{1}$ is evidence for the validity of the model. The static and room-temperature thermal mean-square displacements are plotted as a function of short-range order for $\mathrm{Cu}_{3} \mathrm{Au}$ in fig. 4. The strong short-range-order dependence of the static mean-square displacements is to be contrasted with the weak dependence of the thermal displacements.

Fig. 9

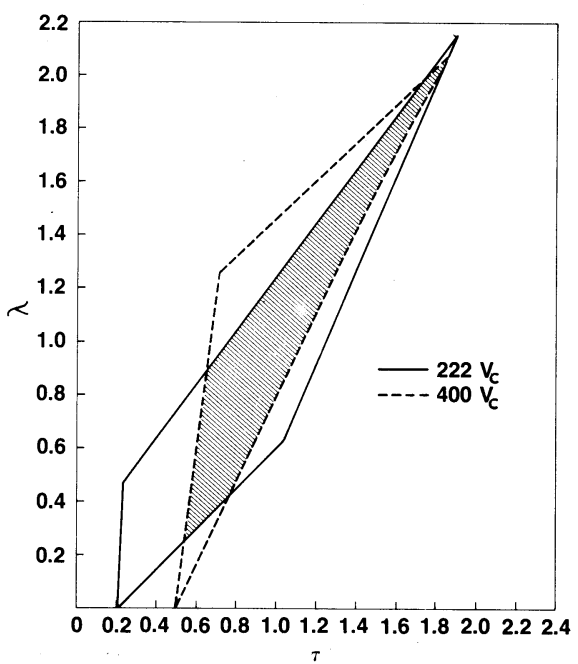

Bounds on possible values of $\gamma$ and $\tau$ for $\mathrm{Cu}(85)-\mathrm{Al}$ as deduced from the data in table 5 .

\section{4. $C u A l$}

The Cu-rich solid solution has a moderate atomic radius mismatch $(6 \%)$ and an ordering tendency. Analysis of the data in table 5 leads to the $\gamma-\tau$ areas in fig. 9. The shaded overlap region gives the range of values consistent with the data. The large range in $\gamma$ is a consequence of the relatively small static mean-square displacement which leads to large proportional errors in parameters deduced therefrom. The data do not give any indication of the degree of order.

\section{§ 4. SURVEY OF CRITICAL VOLTAGE SENSITIVITIES}

The definitions of $\gamma$ and $\tau$ are such that deviations from unity represent deviations from an ideal. Thus, the model with $\gamma=1$ and $\tau=1$ represents a best estimate for the variation of the critical voltages with composition, shortrange order and temperature in a solid solution for which no data are available. 
Table 6. Critical-voltage sensitivities to composition for dilute f.c.c. solid solutions. $\gamma=1, \tau=1$ assumed, except where indicated with asterisk.

\begin{tabular}{|c|c|c|c|}
\hline \multirow{2}{*}{$\begin{array}{l}\text { Solvent and } \\
\text { critical } \\
\text { voltages }\end{array}$} & \multirow{2}{*}{ Solute } & \multicolumn{2}{|c|}{$\underset{\text { solute }}{\Delta V_{\mathrm{c}}(\mathrm{kV}) \text { per mol. } \%}$} \\
\hline & & 400 & 222 \\
\hline \multirow[t]{2}{*}{$\mathrm{Ag}$} & $\mathrm{Al}$ & $3 \cdot 31$ & $2 \cdot 19$ \\
\hline & $\mathrm{Au} *$ & $-1 \cdot 54$ & $-1 \cdot 17$ \\
\hline \multirow{2}{*}{$V_{\mathrm{c}}(400)=221 \mathrm{kV}$} & $\mathrm{Cd}$ & $0 \cdot 18$ & $0 \cdot 16$ \\
\hline & $\mathrm{Cu}$ & $1 \cdot 29$ & 0.91 \\
\hline \multirow[t]{6}{*}{$V_{\mathrm{c}}(222)=54 \mathrm{kV}$} & $\mathrm{Mg}$ & $4 \cdot 38$ & $3 \cdot 17$ \\
\hline & $\mathrm{Mn}$ & $2 \cdot 71$ & $1 \cdot 80$ \\
\hline & $\mathrm{Pd}^{*}$ & $-0 \cdot 26$ & $-0 \cdot 65$ \\
\hline & $\mathrm{Pt}$ & $-2 \cdot 81$ & $-2 \cdot 67$ \\
\hline & Sn & $-0 \cdot 63$ & -0.55 \\
\hline & $\mathrm{Zn}$ & $2 \cdot 96$ & $2 \cdot 14$ \\
\hline \multirow{3}{*}{$\begin{array}{c}\mathrm{Al} \\
V_{\mathrm{c}}(400)=911 \mathrm{kV} \\
V_{\mathrm{c}}(222)=436 \mathrm{kV}\end{array}$} & $\mathrm{Ag}$ & $-12 \cdot 16$ & $-4 \cdot 97$ \\
\hline & $\mathrm{Mg}$ & $1 \cdot 21$ & 1.59 \\
\hline & $\mathrm{Zn}$ & $0 \cdot 81$ & $1 \cdot 71$ \\
\hline \multirow[t]{2}{*}{$\mathrm{Au}$} & $\mathrm{Ag}^{*}$ & $0 \cdot 79$ & - \\
\hline & $\mathrm{Cd}$ & $1 \cdot 10$ & - \\
\hline \multirow[t]{2}{*}{$V_{\mathrm{c}}(400)=110 \mathrm{kV}$} & $\mathrm{Cr}$ & $2 \cdot 92$ & - \\
\hline & $\mathrm{Cu}^{*}$ & $2 \cdot 48$ & - \\
\hline \multirow[t]{7}{*}{$V_{\mathrm{c}}(222)<0$} & $\mathrm{Fe}$ & $2 \cdot 50$ & - \\
\hline & $\mathrm{Mg}$ & $4 \cdot 07$ & - \\
\hline & $\mathrm{Mn}$ & $2 \cdot 82$ & - \\
\hline & $\mathrm{Ni}^{*}$ & $2 \cdot 88$ & - \\
\hline & $\mathrm{Pd}^{*}$ & 0.95 & - \\
\hline & $\mathrm{Pt}$ & -0.99 & - \\
\hline & $\mathrm{Zn}$ & $2 \cdot 85$ & - \\
\hline \multirow[t]{2}{*}{ Co } & $\mathrm{Cr}$ & $0 \cdot 001$ & 0.70 \\
\hline & $\mathrm{Cu}$ & $0 \cdot 50$ & $0 \cdot 39$ \\
\hline \multirow[t]{2}{*}{$V_{\mathrm{c}}(400)=555 \mathrm{kV}$} & $\mathrm{Fe}$ & $0 \cdot 20$ & $-0 \cdot 18$ \\
\hline & $\mathrm{Mn}$ & -0.59 & -0.41 \\
\hline \multirow[t]{5}{*}{$V_{\mathrm{c}}(222)=279 \mathrm{kV}$} & $\mathrm{Ni}$ & $0 \cdot 33$ & $0 \cdot 18$ \\
\hline & $\mathrm{Pd}$ & $-7 \cdot 16$ & $-5 \cdot 34$ \\
\hline & $\mathrm{Pt}$ & $-12 \cdot 66$ & $-9 \cdot 42$ \\
\hline & $\mathrm{V}$ & $-0 \cdot 79$ & $-1 \cdot 12$ \\
\hline & $\mathrm{Zn}$ & 0.98 & $0 \cdot 83$ \\
\hline \multirow[t]{2}{*}{$\mathrm{Cu}$} & $\mathrm{Al}$ & 2.95 & 1.53 \\
\hline & $\mathrm{Au}^{*}$ & $-13 \cdot 38$ & $-9 \cdot 05$ \\
\hline \multirow[t]{2}{*}{$V_{\mathrm{c}}(400)=602 \mathrm{kV}$} & $\mathrm{Ge}$ & $-1 \cdot 11$ & $-1 \cdot 09$ \\
\hline & $\mathrm{Mn}$ & $-1 \cdot 11$ & -0.79 \\
\hline \multirow[t]{6}{*}{$V_{\mathrm{c}}(222)=316 \mathrm{kV}$} & $\mathrm{Ni}^{*}$ & $0 \cdot 07$ & -0.07 \\
\hline & $\mathrm{Pd}$ & $-7 \cdot 41$ & $-5 \cdot 73$ \\
\hline & $\mathrm{Pt}$ & $-13 \cdot 45$ & $-10 \cdot 19$ \\
\hline & $\mathrm{Si}$ & $3 \cdot 00$ & $1 \cdot 34$ \\
\hline & Sn & $-15 \cdot 54$ & $-10 \cdot 38$ \\
\hline & $\mathrm{Zn}$ & $0 \cdot 76$ & $0 \cdot 63$ \\
\hline
\end{tabular}


Table 6 (continued)

\begin{tabular}{|c|c|c|c|}
\hline \multirow{2}{*}{$\begin{array}{l}\text { Solvent and } \\
\text { critical } \\
\text { voltages }\end{array}$} & \multirow{2}{*}{ Solute } & \multicolumn{2}{|c|}{$\begin{array}{c}\Delta V_{\mathrm{c}}(\mathrm{kV}) \text { per mol. } \% \\
\text { solute }\end{array}$} \\
\hline & & 400 & 222 \\
\hline \multirow[t]{2}{*}{$\mathrm{Ni}$} & $\mathrm{Al}$ & $3 \cdot 19$ & $1 \cdot 71$ \\
\hline & $\mathrm{Au} *$ & -15.55 & $-10 \cdot 00$ \\
\hline \multirow[t]{2}{*}{$V_{\mathrm{c}}(400)=589 \mathrm{kV}$} & Co & $-0 \cdot 35$ & $-0 \cdot 20$ \\
\hline & $\mathrm{Cr}$ & $-0 \cdot 21$ & -0.78 \\
\hline \multirow{11}{*}{$V_{\mathrm{c}}(222)=297 \mathrm{kV}$} & $\mathrm{Cu}^{*}$ & $0 \cdot 25$ & $0 \cdot 25$ \\
\hline & $\mathrm{Fe}$ & $-0 \cdot 28$ & -0.41 \\
\hline & Mo & $-6 \cdot 55$ & $-5 \cdot 36$ \\
\hline & $\mathrm{Nb}$ & $-9 \cdot 45$ & $-6 \cdot 95$ \\
\hline & $\mathrm{Pd}$ & $-8 \cdot 43$ & $-6 \cdot 00$ \\
\hline & $\mathrm{Pt}$ & $-14 \cdot 52$ & $-10 \cdot 41$ \\
\hline & $\mathrm{Si}$ & $2 \cdot 21$ & 0.83 \\
\hline & $\mathrm{Sn}$ & $-13 \cdot 54$ & $-8 \cdot 82$ \\
\hline & V & $-1 \cdot 19$ & $-1 \cdot 39$ \\
\hline & W & $-9 \cdot 10$ & $-6 \cdot 62$ \\
\hline & $\mathrm{Zn}$ & 0.58 & $0 \cdot 61$ \\
\hline \multirow[t]{2}{*}{$\mathrm{Pd}$} & $\mathrm{Ag}^{*}$ & $0 \cdot 27$ & - \\
\hline & $\mathrm{Al}$ & $3 \cdot 60$ & - \\
\hline \multirow[t]{2}{*}{$V_{\mathrm{c}}(400)=192 \mathrm{kV}$} & $\mathrm{Au}$ & $-0 \cdot 77$ & - \\
\hline & Co & $2 \cdot 17$ & - \\
\hline \multirow[t]{5}{*}{$V_{\dot{\mathrm{e}}}(222)<0$} & $\mathrm{Cr}$ & $2 \cdot 65$ & - \\
\hline & $\mathrm{Cu}$ & $2 \cdot 32$ & - \\
\hline & Mo & $0 \cdot 21$ & - \\
\hline & $\mathrm{Ni}$ & $2 \cdot 33$ & - \\
\hline & V & $2 \cdot 05$ & - \\
\hline \multirow[t]{2}{*}{$\mathrm{Pt}$} & $\mathrm{Au}$ & -0.63 & - \\
\hline & Co & $2 \cdot 23$ & - \\
\hline \multirow[t]{2}{*}{$V_{\mathrm{c}}(400)=31 \mathrm{kV}$} & $\mathrm{Cr}$ & 2.59 & - \\
\hline & $\mathrm{Cu}$ & $2 \cdot 39$ & - \\
\hline \multirow[t]{2}{*}{$V_{\mathrm{c}}(222)<0$} & $\mathrm{Ni}$ & $2 \cdot 30$ & - \\
\hline & V & $2 \cdot 08$ & - \\
\hline
\end{tabular}

* See table 10.

We have taken advantage of this to carry out a survey of the composition and short-range order sensitivities of the critical voltages for a large number of alloys. The results of this survey, presented in tables $6,7,8$ and 9 , give an indication of which alloys and which phenomena might be studied most effectively by the critical-voltage technique.

The best available parameters were used in the calculation of the sensitivities. Critical voltage-determined pure-metal atomic scattering factors and Debye temperatures were used wherever possible (Thomas et al. 1974). Otherwise, free-atom relativistic Hartree-Fock or Thomas-Fermi-Dirac scattering factors were used (Doyle and Turner 1968, Hirsch, Howie, Nicholson, 
Table 7. Critical-voltage sensitivities to composition for dilute b.c.c. solid solutions. $\gamma=1, \tau=1$ assumed except where indicated by asterisk.

\begin{tabular}{|c|c|c|c|}
\hline \multirow{2}{*}{$\begin{array}{l}\text { Solvent and } \\
\text { critical } \\
\text { voltages }\end{array}$} & \multirow{2}{*}{ Solute } & \multicolumn{2}{|c|}{$\begin{array}{c}\Delta V_{\mathrm{c}}(\mathrm{kV}) \text { per mol. } \% \\
\text { solute }\end{array}$} \\
\hline & & 220 & 400 \\
\hline \multirow[t]{2}{*}{$\mathrm{Cr}$} & $\mathrm{Al}$ & $0 \cdot 68$ & 1.55 \\
\hline & Co & $0 \cdot 88$ & $0 \cdot 14$ \\
\hline \multirow{2}{*}{$V_{\mathrm{c}}(220)=264 \mathrm{kV}$} & $\mathrm{Fe}^{*}$ & $0 \cdot 21$ & $-0 \cdot 78$ \\
\hline & $\mathrm{Mn}$ & $0 \cdot 41$ & $-0 \cdot 38$ \\
\hline \multirow[t]{3}{*}{$V_{c}(400)=1298 \mathrm{kV}$} & Mo & $-7 \cdot 42$ & $-20 \cdot 65$ \\
\hline & $\mathrm{Ni}$ & 0.96 & 0.07 \\
\hline & $\mathrm{V}$ & $-0 \cdot 68$ & $-1 \cdot 77$ \\
\hline \multirow[t]{2}{*}{$\mathrm{Fe}$} & $\mathrm{Al}$ & $1 \cdot 57$ & $5 \cdot 06$ \\
\hline & Co & $0 \cdot 36$ & -0.34 \\
\hline \multirow{2}{*}{$V_{\mathrm{c}}(220)=304 \mathrm{kV}$} & $\mathrm{Cr} *$ & $-0 \cdot 75$ & $-1 \cdot 23$ \\
\hline & $\mathrm{Ge}$ & $-1 \cdot 12$ & $-3 \cdot 03$ \\
\hline \multirow[t]{6}{*}{$V_{\mathrm{c}}(400)=1294 \mathrm{kV}$} & Mo & $-6 \cdot 91$ & $-15 \cdot 67$ \\
\hline & $\mathrm{Ni}$ & $0 \cdot 63$ & $0 \cdot 16$ \\
\hline & $\mathrm{Si}$ & $1 \cdot 02$ & $5 \cdot 19$ \\
\hline & $\mathrm{Sn}$ & $-19 \cdot 24$ & $-62 \cdot 66$ \\
\hline & $\mathrm{V}$ & -0.92 & $-1 \cdot 13$ \\
\hline & $\mathrm{Zn}$ & $0 \cdot 39$ & $-1 \cdot 63$ \\
\hline \multirow{2}{*}{$\begin{array}{c}\mathrm{Nb} \\
V_{\mathrm{c}}(220)=35 \mathrm{kV} \\
V_{\mathrm{c}}(400)=750 \mathrm{kV}\end{array}$} & V & $0 \cdot 73$ & $+1 \cdot 84$ \\
\hline & & & \\
\hline \multirow{3}{*}{$\begin{array}{c}\mathrm{V} \\
V_{\mathrm{c}}(220)=229 \mathrm{kV}\end{array}$} & Co & $0 \cdot 83$ & -0.98 \\
\hline & $\mathrm{Cr}$ & $-0 \cdot 43$ & $-2 \cdot 12$ \\
\hline & $\mathrm{Nb}$ & $-6 \cdot 11$ & $-18 \cdot 00$ \\
\hline \multirow[t]{3}{*}{$V_{\mathrm{c}}(400)=1235 \mathrm{kV}$} & $\mathrm{Ni}$ & 0.90 & -0.78 \\
\hline & $\mathrm{Pd}$ & $-3 \cdot 14$ & $-9 \cdot 36$ \\
\hline & $\mathrm{Pt}$ & $-6 \cdot 24$ & $-18 \cdot 01$ \\
\hline
\end{tabular}

* See table 10.

Pashley and Whelan 1965), and Debye temperatures were taken from the International Tables for X-ray Crystallography (1962). Values assumed for the model parameters were $\gamma=1$ and $\tau=1$ except for the alloys in table 10 . The lattice parameter is given by a parabolic best fit to the lattice parameter data of Pearson (1958). This means that $\eta$ can vary somewhat with composition.

The composition sensitivities in tables 6 and 7 were evaluated at zero solute concentration by taking the derivative with respect to concentration numerically. The pure-metal critical voltages calculated by the program are also given. 
Table 8. Critical-voltage sensitivities to short-range order for concentrated f.c.c. solid solutions. $\quad \gamma=1, \tau=1$ assumed except where indicated by asterisk.

\begin{tabular}{|c|c|c|c|c|c|c|c|}
\hline \multirow{2}{*}{ Solvent } & \multirow{2}{*}{ Solute } & \multirow{2}{*}{$\begin{array}{c}\text { Mol. \% } \\
\text { solute }(x)\end{array}$} & \multirow{2}{*}{$\begin{array}{l}100|\eta| \\
(\text { at } x)\end{array}$} & \multicolumn{2}{|c|}{$100 d\left(\ln V_{\mathrm{c}}\right) / d \alpha_{1}$} & \multicolumn{2}{|c|}{$V_{\mathrm{c}}(\mathrm{kV})$ at $x$} \\
\hline & & & & 400 & 222 & 400 & 222 \\
\hline $\mathrm{Ag}$ & $\mathrm{Al}$ & 15 & $2 \cdot 95$ & $-2 \cdot 12$ & $-4 \cdot 18$ & 275 & 89 \\
\hline $\mathrm{Ag}$ & $\mathrm{Au}^{*}$ & 50 & $0 \cdot 18$ & $2 \cdot 91$ & - & 156 & $\simeq 0$ \\
\hline $\mathrm{Ag}$ & Cd & 40 & $6 \cdot 30$ & $-21 \cdot 94$ & $-54 \cdot 00$ & 231 & 62 \\
\hline $\mathrm{Ag}$ & $\mathrm{Cu}$ & 10 & $8 \cdot 30$ & $-13 \cdot 39$ & $-31 \cdot 14$ & 240 & 67 \\
\hline $\mathrm{Ag}$ & $\mathrm{Mg}$ & 15 & $2 \cdot 25$ & $-1 \cdot 19$ & $-2 \cdot 11$ & 293 & 105 \\
\hline $\mathrm{Ag}$ & $\mathrm{Mn}$ & 15 & $1 \cdot 30$ & $-0 \cdot 38$ & -0.96 & 265 & 83 \\
\hline $\mathrm{Ag}$ & $\mathrm{Pd}^{*}$ & 50 & $4 \cdot 90$ & $-18 \cdot 05$ & $-105 \cdot 30$ & 206 & 22 \\
\hline $\mathrm{Ag}$ & $\mathrm{Pt}$ & 25 & $5 \cdot 21$ & $-16 \cdot 44$ & - & 158 & $<0$ \\
\hline $\mathrm{Ag}$ & Sn & 10 & $10 \cdot 88$ & $-25 \cdot 62$ & $-73 \cdot 47$ & 215 & 49 \\
\hline $\mathrm{Ag}$ & $\mathrm{Zn}$ & 35 & 4.99 & $-10 \cdot 19$ & $-16 \cdot 29$ & 341 & 138 \\
\hline Al & $\mathrm{Ag}$ & 5 & $0 \cdot 20$ & -0.02 & -0.05 & 851 & 411 \\
\hline $\mathrm{Al}$ & $\mathrm{Mg}$ & 15 & $11 \cdot 28$ & $-15 \cdot 56$ & $-17 \cdot 03$ & 934 & 461 \\
\hline $\mathrm{Al}$ & $\mathrm{Zn}$ & 30 & $1 \cdot 50$ & -0.56 & -0.58 & 904 & 467 \\
\hline $\mathrm{Au}$ & $\mathrm{Cd}$ & 20 & $4 \cdot 51$ & $-12 \cdot 29$ & - & 133 & $<0$ \\
\hline $\mathrm{Au}$ & $\mathrm{Cr}$ & 30 & $4 \cdot 03$ & $-9 \cdot 45$ & - & 205 & $\simeq 0$ \\
\hline $\mathrm{Au}$ & $\mathrm{Cu} *$ & 50 & $11 \cdot 96$ & $-152 \cdot 50$ & $-375 \cdot 00$ & 237 & 63 \\
\hline $\mathrm{Au}$ & $\mathrm{Fe}$ & 30 & $9 \cdot 17$ & $-50 \cdot 26$ & $-315 \cdot 70$ & 185 & 19 \\
\hline $\mathrm{Au}$ & $\mathrm{Mg}$ & 15 & $1 \cdot 63$ & -0.97 & $-6 \cdot 83$ & 177 & 17 \\
\hline $\mathrm{Au}$ & $\mathrm{Mn}$ & 20 & $1 \cdot 54$ & $-1 \cdot 16$ & $-10 \cdot 76$ & 172 & 12 \\
\hline $\mathrm{Au}$ & $\mathrm{Ni}^{*}$ & 10 & $10 \cdot 32$ & $-60 \cdot 32$ & - & 136 & $<0$ \\
\hline $\mathrm{Au}$ & $\mathrm{Pd}^{*}$ & 50 & $4 \cdot 74$ & $-24 \cdot 84$ & - & 152 & $<0$ \\
\hline $\mathrm{Au}$ & $\mathrm{Pt}$ & 30 & $4 \cdot 04$ & $-20 \cdot 22$ & - & 82 & $<0$ \\
\hline $\mathrm{Au}$ & $\mathrm{Zn}$ & 15 & $5 \cdot 06$ & $-10 \cdot 81$ & - & 155 & $\simeq 0$ \\
\hline Co & $\mathrm{Cr}$ & 20 & $0 \cdot 34$ & -0.04 & -0.04 & 554 & 264 \\
\hline Co & $\mathrm{Cu}$ & 10 & 1.99 & -0.51 & -0.57 & 560 & 282 \\
\hline Co & $\mathrm{Fe}$ & 15 & $2 \cdot 54$ & $-1 \cdot 10$ & $-1 \cdot 33$ & 558 & 276 \\
\hline Co & $\mathrm{Mn}$ & 50 & $8 \cdot 59$ & $-24 \cdot 57$ & $-30 \cdot 87$ & 549 & 269 \\
\hline Co & $\mathrm{Ni}$ & 50 & 0.57 & $-0 \cdot 10$ & $-0 \cdot 16$ & 572 & 288 \\
\hline Co & $\mathrm{Pd}$ & 50 & $9 \cdot 24$ & -38.92 & $-77 \cdot 72$ & 318 & 98 \\
\hline Co & $\mathrm{Pt}$ & 50 & $9 \cdot 78$ & $-67 \cdot 67$ & - & 179 & $<0$ \\
\hline Co & $\mathrm{V}$ & 10 & $4 \cdot 61$ & -2.57 & $-3 \cdot 20$ & 547 & 267 \\
\hline Co & $\mathrm{Zn}$ & 15 & $7 \cdot 13$ & $-8 \cdot 75$ & $-10 \cdot 66$ & 570 & 291 \\
\hline $\mathrm{Cu}$ & $\mathrm{Al}$ & 15 & $5 \cdot 86$ & $-5 \cdot 12$ & $-6 \cdot 09$ & 645 & 339 \\
\hline $\mathrm{Cu}$ & $\mathrm{Ge}$ & 10 & $9 \cdot 60$ & $-10 \cdot 96$ & $-13 \cdot 20$ & 587 & 305 \\
\hline $\mathrm{Cu}$ & $\mathrm{Mn}$ & 40 & $5 \cdot 03$ & $-7 \cdot 96$ & $-9 \cdot 59$ & 596 & 305 \\
\hline $\mathrm{Cu}$ & $\mathrm{Ni} *$ & 50 & $2 \cdot 53$ & $-2 \cdot 77$ & $-3 \cdot 33$ & 599 & 309 \\
\hline $\mathrm{Cu}$ & $\mathrm{Pd}$ & 50 & $7 \cdot 36$ & $-24 \cdot 08$ & $-44 \cdot 83$ & 336 & 111 \\
\hline $\mathrm{Cu}$ & $\mathrm{Pt}$ & 50 & $8 \cdot 17$ & $-44 \cdot 89$ & - & 195 & $\simeq 0$ \\
\hline $\mathrm{Cu}$ & $\mathrm{Si}$ & 10 & $1 \cdot 79$ & -0.33 & -0.43 & 632 & 329 \\
\hline $\mathrm{Cu}$ & $\mathrm{Sn}$ & 10 & $28 \cdot 16$ & $-99 \cdot 37$ & $-131 \cdot 72$ & 464 & 224 \\
\hline $\mathrm{Cu}$ & $\mathrm{Zn}$ & 30 & $6 \cdot 72$ & $-12 \cdot 35$ & -14.55 & 624 & 335 \\
\hline $\mathrm{Ni}$ & $\mathrm{Al}$ & 20 & $1 \cdot 50$ & -0.45 & -0.51 & 658 & 332 \\
\hline $\mathrm{Ni}$ & $\mathrm{Au}^{*}$ & 20 & $17 \cdot 95$ & $-137 \cdot 40$ & $212 \cdot 84$ & 367 & 151 \\
\hline $\mathrm{Ni}$ & $\mathrm{Cr}$ & 40 & $4 \cdot 17$ & $-5 \cdot 67$ & $-7 \cdot 29$ & 575 & 263 \\
\hline
\end{tabular}

(continued over) 
Table 8 (continued)

\begin{tabular}{|c|c|c|c|c|c|c|c|}
\hline \multirow{2}{*}{ Solvent } & \multirow{2}{*}{ Solute } & \multirow{2}{*}{$\begin{array}{c}\text { Mol. } \% \\
\text { solute }(x)\end{array}$} & \multirow{2}{*}{$\begin{array}{c}100|\eta| \\
(\text { at } x)\end{array}$} & \multicolumn{2}{|c|}{$100 d\left(\ln V_{\mathrm{c}}\right) / d \alpha_{1}$} & \multicolumn{2}{|c|}{$V_{\mathrm{c}}(\mathrm{kV})$ at $x$} \\
\hline & & & & 400 & 222 & 400 & 222 \\
\hline $\mathrm{Ni}$ & $\mathrm{Fe}$ & 50 & $0 \cdot 76$ & $-0 \cdot 19$ & $-0 \cdot 23$ & 583 & 279 \\
\hline $\mathrm{Ni}$ & Mo & 20 & $8 \cdot 54$ & $-17 \cdot 81$ & $-25 \cdot 21$ & 466 & 199 \\
\hline $\mathrm{Ni}$ & $\mathrm{Nb}$ & 10 & $16 \cdot 78$ & $-35 \cdot 88$ & $-47 \cdot 63$ & 501 & 233 \\
\hline $\mathrm{Ni}$ & $\mathrm{Pd}$ & 50 & $9 \cdot 79$ & $-43 \cdot 31$ & $-84 \cdot 60$ & 325 & 102 \\
\hline $\mathrm{Ni}$ & $\mathrm{Pt}$ & 50 & $10 \cdot 65$ & $-78 \cdot 86$ & - & 183 & $\simeq 0$ \\
\hline $\mathrm{Ni}$ & $\mathrm{Si}$ & 15 & $0 \cdot 33$ & -0.02 & -0.02 & 626 & 312 \\
\hline $\mathrm{Ni}$ & Sn & 10 & $23 \cdot 54$ & $-72 \cdot 11$ & -96.98 & 475 & 221 \\
\hline $\mathrm{Ni}$ & V & 30 & $-8 \cdot 53$ & $-20 \cdot 22$ & $-26 \cdot 30$ & 543 & 251 \\
\hline $\mathrm{Ni}$ & W & 15 & $11 \cdot 56$ & $-28 \cdot 14$ & -38.97 & 468 & 209 \\
\hline $\mathrm{Ni}$ & $\mathrm{Zn}$ & 30 & $7 \cdot 15$ & $-14 \cdot 24$ & $-17 \cdot 02$ & 609 & 317 \\
\hline $\mathrm{Pd}$ & $\mathrm{Al}$ & 15 & 0.00 & -0.04 & 0.00 & 250 & 32 \\
\hline $\mathrm{Pd}$ & $\mathrm{Cr}$ & 40 & $2 \cdot 17$ & $-2 \cdot 17$ & -5.95 & 309 & 68 \\
\hline $\mathrm{Pd}$ & Mo & 35 & $3 \cdot 76$ & $-14 \cdot 61$ & - & 197 & $<0$ \\
\hline $\mathrm{Pd}$ & $\mathrm{V}$ & 50 & $2 \cdot 17$. & $-2 \cdot 20$ & $-5 \cdot 42$ & 316 & 76 \\
\hline $\mathrm{Pt}$ & $\mathrm{Au}$ & 15 & $3 \cdot 56$ & $-18 \cdot 10$ & - & 40 & $<0$ \\
\hline $\mathrm{Pt}$ & $\mathrm{Cr}$ & 30 & $5 \cdot 72$ & $-28 \cdot 06$ & - & 117 & $<0$ \\
\hline $\mathrm{Pt}$ & V & 20 & $5 \cdot 56$ & $-28 \cdot 15$ & - & 77 & $<0$ \\
\hline
\end{tabular}

* See table 10.

Table 9. Critical-voltage sensitivities to short-range order for concentrated b.c.c. solid solutions. $\quad \gamma=1, \tau=1$ assumed except where indicated by asterisk.

\begin{tabular}{|c|c|c|c|c|c|c|c|}
\hline \multirow{2}{*}{ Solvent } & \multirow{2}{*}{ Solute } & \multirow{2}{*}{$\begin{array}{c}\text { Mol. \% } \\
\text { solute }(x)\end{array}$} & \multirow{2}{*}{$\begin{array}{l}100|\eta| \\
(\text { at } x)\end{array}$} & \multicolumn{2}{|c|}{$100 d\left(\ln V_{\mathrm{c}}\right) / d \alpha_{1}$} & \multicolumn{2}{|c|}{$V_{\mathrm{c}}(\mathrm{kV})$ at $x$} \\
\hline & & & & 220 & 400 & 220 & 400 \\
\hline $\mathrm{Cr}$ & $\mathrm{Al}$ & 15 & $8 \cdot 28$ & $-4 \cdot 43$ & $-3 \cdot 75$ & 278 & 1334 \\
\hline $\mathrm{Cr}$ & Co & 15 & $3 \cdot 49$ & $-1 \cdot 20$ & -0.97 & 273 & 1281 \\
\hline $\mathrm{Cr}$ & $\mathrm{Fe}^{*}$ & 50 & 0.52 & $3 \cdot 47$ & $2 \cdot 78$ & 277 & 1268 \\
\hline $\mathrm{Cr}$ & $\mathrm{Mn}$ & 50 & $0 \cdot 13$ & -0.03 & -0.02 & 283 & 1272 \\
\hline $\mathrm{Cr}$ & Mo & 50 & $8 \cdot 74$ & $-32 \cdot 62$ & $-11 \cdot 96$ & 84 & 867 \\
\hline $\mathrm{Cr}$ & $\mathrm{Ni}$ & 10 & $1 \cdot 65$ & $-0 \cdot 23$ & $-0 \cdot 15$ & 274 & 1298 \\
\hline $\mathrm{Cr}$ & V & 50 & $4 \cdot 87$ & $-4 \cdot 62$ & $-3 \cdot 35$ & 233 & 1219 \\
\hline $\mathrm{Fe}$ & $\mathrm{Al}$ & 20 & $3 \cdot 26$ & $-0 \cdot 68$ & -0.73 & 433 & 1429 \\
\hline $\mathrm{Fe}$ & Co & 40 & 1.05 & $-0 \cdot 15$ & $-0 \cdot 14$ & 317 & 1274 \\
\hline $\mathrm{Fe}$ & $\mathrm{Ge}$ & 20 & $1 \cdot 10$ & $-0 \cdot 15$ & $-0 \cdot 13$ & 301 & 1303 \\
\hline $\mathrm{Fe}$ & Mo & 10 & $9 \cdot 81$ & -7.92 & $-6 \cdot 04$ & 241 & 1152 \\
\hline $\mathrm{Fe}$ & $\mathrm{Ni}$ & 10 & $0 \cdot 45$ & 0.00 & 0.00 & 311 & 1297 \\
\hline $\mathrm{Fe}$ & $\mathrm{Si}$ & 20 & $6 \cdot 97$ & $-3 \cdot 86$ & $-3 \cdot 31$ & 307 & 1342 \\
\hline $\mathrm{Fe}$ & $\mathrm{Sn}$ & 10 & $23 \cdot 92$ & $-62 \cdot 65$ & $-37 \cdot 48$ & 154 & 827 \\
\hline $\mathrm{Fe}$ & V & 30 & 3.91 & $-2 \cdot 19$ & -1.74 & 271 & 1238 \\
\hline $\mathrm{Fe}$ & $\mathrm{Zn}$ & 30 & $9 \cdot 43$ & $-12 \cdot 79$ & $-10 \cdot 32$ & 298 & 1183 \\
\hline $\mathrm{Nb}$ & $\mathrm{V}$ & 50 & $8 \cdot 55$ & $-32 \cdot 57$ & $-11 \cdot 02$ & 77 & 844 \\
\hline $\mathrm{V}$ & Co & 10 & $4 \cdot 45$ & $-1 \cdot 50$ & $-1 \cdot 13$ & 238 & 1226 \\
\hline V & $\mathrm{Ni}$ & 10 & $5 \cdot 01$ & $-2 \cdot 02$ & $-1 \cdot 48$ & 238 & 1228 \\
\hline V & $\mathrm{Pd}$ & 20 & $4 \cdot 87$ & $-4 \cdot 67$ & $-2 \cdot 92$ & 172 & 1068 \\
\hline $\mathrm{V}$ & $\mathrm{Pt}$ & 10 & $5 \cdot 78$ & $-5 \cdot 40$ & $-3 \cdot 38$ & 171 & 1068 \\
\hline
\end{tabular}

* See table 10. 
Table 10. Known values of $\tau$ and $\gamma$ used in tables 6, 7, 8 and 9, except values of $\gamma$ in parentheses, which are assumed.

\begin{tabular}{lccl}
\hline Alloy & $\gamma$ & $\tau$ & \multicolumn{1}{c}{ Reference } \\
\hline AgAu & $(1.00)$ & $0 \cdot 90$ & Shirley (1975) \\
AgPd & $(1 \cdot 00)$ & $1 \cdot 16$ & Shirley (1975) \\
AuCu & $1 \cdot 34$ & $1 \cdot 76$ & Present paper \\
AuNi & $1 \cdot 23$ & $1 \cdot 87$ & Present paper \\
AuPd & $(1 \cdot 00)$ & $1 \cdot 29$ & Shirley (1975) \\
CuNi & $(1 \cdot 00)$ & $1 \cdot 06$ & Shirley (1975) \\
CrFe & $(1 \cdot 00)$ & 0.72 & Shirley et al. $(1975)$ \\
\hline
\end{tabular}

The short-range order sensitivities were evaluated for solid solutions near their solubility limit or at $50 \mathrm{~mol} \%$ for solutions with complete solubility. Tables 8 and 9 should therefore show a short-range order sensitivity near the maximum available in a given solid solution. The fourth column in tables 8 and $9(100|\eta|)$ gives the effective percentage difference in atomic radii at the tabulated composition. The fifth and sixth columns give the percentage change in the critical voltage for a change of unity in $\alpha_{1}$. These columns were calculated by taking the numerical derivative at the tabulated composition and $\alpha_{1}=0$. The final two columns give the critical voltages at the tabulated compositions. Except for $\mathrm{AgAu}$ and $\mathrm{FeCr}$, in which the main effect of shortrange order is through the thermal mean-square displacements (because $\tau \neq 1$, see eqn. (11)), the change in the critical voltage has the opposite sign to the change in $\alpha_{1}$. The percentage change in $V_{\mathrm{c}}$ is given by

$$
\Delta V_{\mathrm{c}}(\%)=100 \frac{d\left(\ln V_{\mathrm{c}}\right)}{d \alpha_{1}} \Delta \alpha_{1}
$$

Using a maximum likely value of $\Delta \alpha_{1}=0.2$ one can see whether a change in $\alpha_{1}$ could be detected through $V_{c}$. For example, with $\Delta \alpha_{1}=0.2$ we find $\Delta V_{\mathrm{c}}=0.4 \%$ for the 400 critical voltage of $\mathrm{Ag}-\mathrm{Al}(15)$, but $\Delta V_{\mathrm{c}}=5 \cdot 1 \%$ for the same reflection in $\mathrm{Ag}-\mathrm{Sn}(10)$. Since changes of 1 or $2 \%$ in $V_{\mathrm{c}}$ can be detected, short-range order is detectable in the latter but not the former. The strong correlation of atomic-radius disparity and concentration with short-range order sensitivity is apparent in the tables. Likely candidates for a critical-voltage short-range-order experiment are those solid solutions with $\left[100 \partial \ln V_{\mathrm{c}} / \partial \alpha_{1}\right] \geqslant 25$ and with a convenient value of $V_{\mathrm{c}}$. There are about 17 f.c.c. solid solutions and one or two b.c.c. solid solutions that fulfil these conditions. These estimates may be conservative since they assume $\gamma=1$ (except where noted in the tables) whereas the values measured for $\mathrm{Cu}-\mathrm{Au}$ and $\mathrm{Ni}-\mathrm{Au}$ are greater than this. If $\gamma>1$ is general, then all sensitivities will increase. The estimates also assume that a $5 \%$ change in $V_{\mathrm{c}}$ is required rather than the 1 or $2 \%$ required for bare detectability. On the other hand, critical voltages are more difficult to measure in alloys with large atomic-radius mismatch than in elemental crystals because of the interference of the strong Huang scattering from these alloys in the diffraction pattern. 
The temperature sensitivities of the critical voltages of the alloys were also computed but are not tabulated since they are not a decisive factor in choosing a system for a critical-voltage study. Suffice it to mention that, in general, it is necessary to know the sample temperature to $\pm 5^{\circ} \mathrm{C}$ in order to have $V_{\text {c }}$ correct to $\pm 1 \%$ or better.

\section{§ 5. Summary AND conclusions}

We have derived a model for the thermal and static mean-square displacements in b.c.c. and f.c.c. alloys which may be used in the analysis of criticalvoltage data. The often large contribution due to static distortions, and its short-range order dependence are important elements in the model.

The model emphasizes the importance of measuring $V_{\mathrm{c}}$ at at least two temperatures, none of which should be high enough for diffusional relaxation to occur in the alloy system of interest.

Critical-voltage data for $\mathrm{Cu}-\mathrm{Au}$ and $\mathrm{Ni}-\mathrm{Au}$ solid solutions show good evidence for the effects of short-range order when analysed in terms of the model.

Concentrated solid solutions with large atomic-radius disparity are candidates for short-range order studies using the critical-voltage technique. A survey of solid solutions reveals about 17 possibilities.

Alloys with small atomic-radius disparity are possibilities for precise critical-voltage measurements of scattering factors to detect charge transfer effects.

\section{ACKNOWLEDGMENTS}

Most of this work was performed while one of us (C.G.S.) was a Visiting Scientist at the U.S. Steel Research Laboratory, and the final calculations were carried out at Motorola. C.G.S. gratefully acknowledges the time and resources provided by both organizations.

\section{REFERENCES}

BeLl, W. L., and Thomas, G., 1972, Electron Microscopy and Structure of Materials, edited by G. Thomas (University of California Press), p. 23.

BorIE, B. S., 1957, Acta crystallogr., 10, 89.

Butler, E. P., 1972, Phil. Mag., 26, 33 ; 1973, Phys. Stat. Sol. (a), 18, 71.

Clapp, P. C., 1968, Phys. Rev., 164, 1018.

Coyle, R. A., and Gale, B., 1955, Acta crystallogr., 8, 105.

Doyle, P. A., and Turner, P. S., 1968, Acta crystallogr. A, 24, 390.

Fisher, P. M. J., 1968, Japan. J. appl. Phys., 7, 191.

Fisher, R. M., Lally, J. S., Humpreys, C. J., and Metherell, A. J. F., 1970, Proceedings of the 7th International Congress for Electron Microscopy, Grenoble, Vol. I (Paris : Société Française de Microscopie Electronique), pp. 107-108.

Fuinn, P. A., and Maradudin, A. A., 1962, Ann. Phys. (N.Y.), 18, 81.

Flocken, J. W., and Hardy, J. R., 1969, Phys. Rev., 177, 1054.

Herbstein, F. H., Borie, B. S., Jr., and Averbach, B. L., 1956, Acta crystallogr., $9,466$.

Hirsch, P. B., Howie, A., Nicholson, R. B., Pashley, D. W., and Whelan, M. J., 1965, Electron Microscopy of Thin Crystals (London: Butterworths).

Humphreys, C. J., and Fisher, R. M., 1971, Acta crystallogr. A, 27, 42.

Krivoglaz, M. A., 1960, Fizika Metall., 10, 169. 
Krivoglaz, M. A., 1969, Theory of X-ray and Thermal Neutron Scattering by Real Crystals (New York: Plenum), Chaps. 6 and 7.

Kuroda, K., Tomokiyo, Y., and Eguchi, T.; 1977, Proceedings of the Fifth International Conference on HVEM (Tokyo: Japanese Society of Electron Microscopy).

Lally, J. S., Humphreys, C. J., Metherell, A. J. F., and Fisher, R. M., 1972, Phil. Mag., 25, 321.

Lonsdale, K., 1962, International Tables for X-ray Crystallography, Vol. III (Birmingham, England: Kynoch Press), p. 232.

Metherell, A. J. F., and Fisher, R. M., 1969, Phys. Stat. Sol., 32, 551.

Moss, S. C., and Averbach, B. L., 1967, Small Angle X-ray Scattering, edited by H. Brumberger (New York: Gordon \& Breach), p. 335.

Moss, S. C., and Clapp, P. C., 1968, Phys. Rev., 171, 764.

Mozer, B., Keating, D. T., and Moss, S. C., 1968, Phys. Rev., 175, 868.

Nagata, F., and Fukuhara, A., 1967, Japan. J. appl. Phys., 6, 1233.

Pearson, W. B., 1958, Handbook of Lattice Spacings and Structures of Metals and Alloys (Pergamon).

Shirley, C. G., 1974, Phys. Rev. B, 10, 1149 ; 1975, Acta crystallogr. A, 31, 853.

ShIrLey, C. G., and Fisher, R. M., 1977, Proceedings U.S.-Japan HVEM Seminar, Honolulu (Nagoya University Press), p. 38.

Shirley, C. G., Lally, J. S., Thomas, L. E., and Fisher, R. M., 1975, Acta crystallogr. $\mathrm{A}, 31,174$.

Shirley, C. G., Thomas, L. E., Lally, J. S., and Fisher, R. M., 1974, Proceedings 8th International Congress on Electron Microscopy, Canberra (Canberra: Australian Academy of Science), p. 346.

Sinclatr, R., Goringe, M. J., and Thomas, G., 1975, Phil. Mag., 32, 501.

Steeds, J. W., Jones, P. M., Rackham, G. M., and Shannon, M. D., 1976, Developments in Electron Microscopy and Analysis, edited by J. A. Venables (New York : Academic Press).

Thomas, L. E., 1972, Phil. Mag., 26, 1447.

Thomas, L. E., Shirley, C. G., Lally, J. S., and Fisher, R. M., 1974, High Voltage Electron Microscopy (London: Academic Press), p. 38.

Uyeda, R., 1968, Acta crystallogr. A, 24, 175.

Warren, B. E., 1969, X-ray Diffraction (Addison-Wesley).

Watanabe, D., Uyeda, R., and Kogiso, M., 1968, Acta crystallogr. A, 24, 249. 